\title{
Article \\ Contamination Levels of Potentially Toxic Elements and Foraminiferal Distribution Patterns in Lagos Lagoon: A Correlation Analysis
}

\author{
Olugbenga T. Fajemila $1, * \mathbb{C}$, Michael Martínez-Colón ${ }^{2}{ }^{\mathbb{D}}$, Nisan Sariaslan ${ }^{3}$, Ivory S. Council ${ }^{2}$, \\ Tesleem O. Kolawole ${ }^{1(D)}$ and Martin R. Langer ${ }^{3}$ \\ 1 Department of Geological Sciences, Osun State University, Osogbo 230261, Nigeria; \\ tesleem.kolawole@uniosun.edu.ng \\ 2 School of the Environment, Florida A\&M University, Tallahassee, FL 32307, USA; \\ michael.martinez@famu.edu (M.M.-C.); ivory.council@famu.edu (I.S.C.) \\ 3 Institut für Geowissenschaften, Paläontologie, Rheinische Friedrich-Wilhelms-Universität, \\ 53115 Bonn, Germany; nisansariaslan@gmail.com (N.S.); martin.langer@uni-bonn.de (M.R.L.) \\ * Correspondence: olugbenga.fajemila@uniosun.edu.ng
}

check for updates

Citation: Fajemila, O.T.;

Martínez-Colón, M.; Sariaslan, N.; Council, I.S.; Kolawole, T.O.; Langer, M.R. Contamination Levels of Potentially Toxic Elements and Foraminiferal Distribution Patterns in Lagos Lagoon: A Correlation Analysis. Water 2022, 14, 37. https://doi.org/10.3390/w14010037

Academic Editor: Arantza Iriarte

Received: 24 November 2021

Accepted: 21 December 2021

Published: 24 December 2021

Publisher's Note: MDPI stays neutral with regard to jurisdictional claims in published maps and institutional affiliations.

Copyright: () 2021 by the authors Licensee MDPI, Basel, Switzerland. This article is an open access article distributed under the terms and conditions of the Creative Commons Attribution (CC BY) license (https:/ / creativecommons.org/licenses/by/ $4.0 /)$.

\begin{abstract}
The ecological response of benthic foraminifera to bioavailable Potentially Toxic Elements (PTEs) was evaluated in Lagos Lagoon (Nigeria). We sampled and analyzed PTEs across Lagos Lagoon with the aim to investigate the extent of contaminated sediments, to document their distribution, and to explore the relationship between PTE concentration and the spatial distribution, composition, abundance, and species richness of benthic foraminifera biotas. PTE's recordings showed a wide range reflecting a diffuse contamination, where Contamination and Enrichment Factor suggest low to extremely polluted sediments. Findings of a previous survey of the benthic foraminifera inhabiting Lagos Lagoon revealed diverse assemblages of benthic taxa, species-specific distribution patterns, gradients of species richness and abundance, and a disjunct distribution of agglutinated and hyaline-perforate/porcelaneous taxa along a pronounced salinity gradient. Correlation matrix analysis shows that except for Selenium, all PTE total concentrations positively correlate with mud and Total Organic Carbon (TOC) and two of the most abundant agglutinated taxa, Ammotium salsum, and Trochammina sp. 1. Moreover, both species display significant positive correlations with $\mathrm{Cr}_{\mathrm{F} 4}-\mathrm{CO}_{\mathrm{F} 2-\mathrm{F} 3-\mathrm{F} 4-\text { total }}-\mathrm{Cu}_{\mathrm{F} 4 \text {-total }}-\mathrm{Ni}_{\mathrm{F} 3-\mathrm{F} 4 \text {-total }}-\mathrm{Al}_{\mathrm{F} 4 \text {-total }}-\mathrm{Fe}_{\mathrm{F} 3-\mathrm{F} 4 \text {-total }}-\mathrm{Zn}_{\mathrm{F} 3-\mathrm{F} 4 \text {-total }}$. On the other hand, both foraminifers correlate negatively with $\mathrm{Pb}_{\mathrm{F} 4}-\mathrm{Se}_{\mathrm{F} 3}-\mathrm{Se}_{\text {total }}$. The overall significant positive correlation of these PTEs suggests that they behave as micronutrients when complexed with organic matter. No significant positive correlation with none of the PTEs in any fraction was found for neither species richness nor for the most abundant hyaline perforate species (Ammonia aoteana). Some PTE fractions were found to correlate either positively or negatively with individual species, suggesting that they function as either micronutrients and/or stressors. The resulting Contamination Factor of the PTE total concentrations shows that only a few sample sites can be classified as "moderately" polluted for chromium, zinc, and copper and that all sampled sites are classified as "highly polluted" for selenium. The highest concentrations for $\mathrm{Cr}, \mathrm{Cu}, \mathrm{Ni}$, and $\mathrm{Zn}$ were found towards the industrialized western part, an area that is characterized by moderate to high diversity but low abundances.
\end{abstract}

Keywords: benthic foraminifera; toxic elements; pollution; Lagos Lagoon; Nigeria

\section{Introduction}

Estuaries with limited exchange with the open ocean are among the most vulnerable marine environments to human disturbance (e.g., [1-3]). By providing shelter and access further inland, they provide ideal settings for harbors, shipyards, commercial infrastructure, and industrial areas, where human activities are concentrated. Estuaries are, however, also direct recipients of municipal waste coupled with urban, industrial, and agricultural 
run-offs. The anthropogenic pressure directly impacts the sediment and water quality and leads to environmental degradation.

Coastal pollution is alarming in Nigeria, especially in areas where hydrocarbon exploration and other industrial activities are common. The Lagos Lagoon area, with an estimated population of 20 million people, has long been under enormous environmental pressure caused by deforestation, industrial effluents, alteration of the natural landscape, sand mining, and waste disposal. The industrial complex around Lagos Lagoon includes textile, brewery, petrochemical factories, logging and metal industry, power plants, paper mills, and sawmills from which untreated effluents drain into the lagoon through creeks and underground canals releasing potentially toxic elements (PTEs) [4-7]. Past studies revealed that Lagos Lagoon is impacted by PTEs arising from industrial and domestic waste disposal [4,7]. High numbers of PTEs, Polycyclic Aromatic Hydrocarbons (PAHs), as well as agricultural run-offs, were found in the western corridor of the lagoon $[4,5,7,8]$.

Benthic foraminifera are known to bioaccumulate PTEs and have been widely utilized as bioindicators of pollution [9-12]. Our previous, large-scale survey of the benthic foraminifera inhabiting Lagos Lagoon revealed diverse assemblages of benthic taxa, speciesspecific distribution patterns, gradients of species richness and abundance, and a disjunct distribution of agglutinated and hyaline-perforate/porcelaneous taxa along a pronounced salinity gradient [13]. Analysis of foraminiferal distribution patterns also suggested that effluents from the oil industry, PAHs, urban sewage, and high concentrations of PTEs are among the agents driving the abundance, composition, species richness, and spatial distribution of benthic foraminifera in the polluted western section of the lagoon. However, to what extent PTEs impact benthic foraminiferal biotas has not been fully resolved. We sampled and analyzed PTEs across Lagos Lagoon with the aim to investigate the extent to which sediments are contaminated, to document their distribution, and to explore the relationship between PTE concentration and the spatial distribution, composition, abundance, and species richness of benthic foraminiferal biotas. The purpose of this study is to assess the ecological impacts of selected PTEs on the assemblage structures and spatial distribution of benthic foraminifera and to provide guidance on the use of foraminifera as bioindicators of PTE pollution in the coastal areas of the Gulf of Guinea (GoG).

\section{Study Area}

Lagos Lagoon is located between longitudes $3^{\circ} 23^{\prime}$ and $3^{\circ} 40^{\prime} \mathrm{E}$ and latitudes $6^{\circ} 22^{\prime}$ and $6^{\circ} 38^{\prime} \mathrm{N}$ (Figure 1) and has a total surface area of $6354.7 \mathrm{~km}^{2}$. It is connected to the Atlantic Ocean through the Commodore Channel, which allows for the mixing of lagoon waters with seawater. The depth of the lagoon is relatively shallow and ranges from 5 to $25 \mathrm{~m} \mathrm{[6]}$. The salinity of the surface waters is highly variable and strongly impacted by seasonality; 0 to $16 \%$ in the wet season and up to $35 \%$ in the dry season especially at the lagoon entrance through the Commodore Channel [7,14-16]. The dissolved oxygen varies between $4-5.5 \mathrm{mg} / \mathrm{L}$ [15-17]. Land conversion for urban development has been mainly conducted along the western lagoon shores, with the remaining marshlands being fringed by the mangrove tree Rhizophora racemosa [18]. Both the Ogun and Osun rivers serve as fresh water sources, but most hinterland sediments and waste water come through the Ogun River (Figure 1). Seawater enters the lagoon during periods of high tide through the channel, but during low tide and especially the wet season, the diluting effect of waters from both rain and hinterland keep the salinity of the lagoon surface waters at comparatively low levels [19]. 


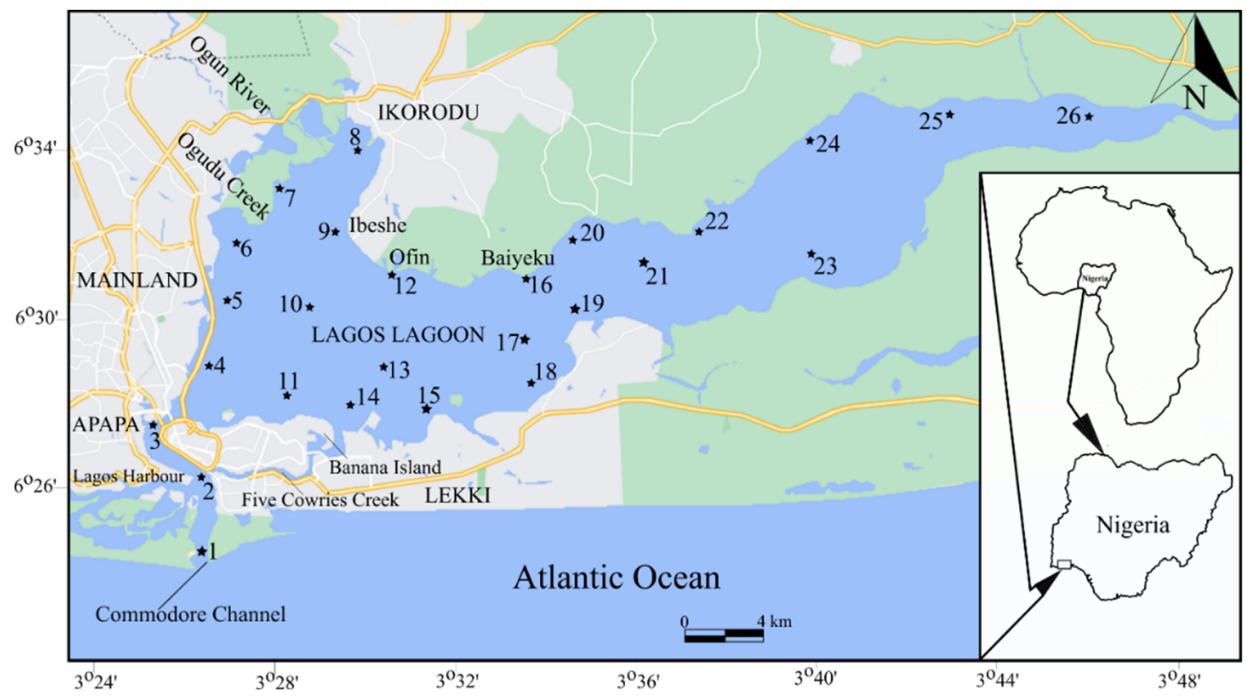

Figure 1. Sample sites within Lagos Lagoon, Nigeria (modified from Google map).

\section{Methods}

\subsection{Processing of Sediment Samples}

Twenty-six stations were sampled within Lagos Lagoon in May 2019 with support from the Nigerian Institute of Oceanography and Marine Research (Figure 1). The top $2 \mathrm{~cm}$ of the bottom sediments were collected, transported to the laboratory, and dried at $50{ }^{\circ} \mathrm{C}$ for $48 \mathrm{~h}$ to ensure complete water loss. The physico-chemical parameters (temperature, salinity, and $\mathrm{pH}$ ) were also measured at the lagoon's water surface using a multi-parameter sensor probe-device (HI 9813-6N, Hanna Instruments, Smithfield, RI, USA) (see [13]).

In the laboratory, sub-samples were taken for percent total organic carbon (TOC), percent calcium carbonate $\left(\% \mathrm{CaCO}_{3}\right)$, grain size, and PTE analyses. The Loss-on-Ignition (LOI) method was used to analyze for TOC and $\% \mathrm{CaCO}_{3}$ using a muffle furnace (Lindberg Blue M, Thermo Scientific, Columbia, MD, USA). This widely used method combusts a sample at two different temperatures to estimate the organic matter and carbonate mass loss (e.g., [20,21]). Each sub-sample was oven-dried at $105^{\circ} \mathrm{C}$ for $24 \mathrm{~h}$, and after cooling to room temperature the sub-samples were combusted at $550{ }^{\circ} \mathrm{C}$ for $4 \mathrm{~h}$ for TOC determination. To assess the $\% \mathrm{CaCO}_{3}$ content, the left-over material from the TOC combustion was baked at $1000{ }^{\circ} \mathrm{C}$ for one hour. For grain size analysis all dry sub-samples were wet-sieved $(63 \mu \mathrm{m})$ and oven-dried at $50{ }^{\circ} \mathrm{C}$ for $24 \mathrm{~h}$ to determine the mud percent content (silt + clay) by weight difference. Following the methods of Martínez-Colón et al. [1], all size fractions were converted to phi $(\Phi)$ units $(-1=$ gravel; $0=$ very coarse sand; $1=$ coarse sand; $2=$ medium sand; 3 = fine sand; $4=$ very fine sand; $>4=$ mud).

For PTE analysis each sub-sample (one gram) was crushed, powdered, and homogenized using an agate mortar and pestle. The residues were then dry-sieved using a $63 \mu \mathrm{m}$ plastic sieve with a Teflon mesh, and the $<63 \mu \mathrm{m}$ size was used for chemical extractions of PTEs. The sequential extraction analytical methods of Tessier et al. [22] were implemented to assess the concentration of the 11 contaminants of concern $(\mathrm{Cr}, \mathrm{Co}, \mathrm{Cu}, \mathrm{Ni}, \mathrm{Cd}, \mathrm{Pb}, \mathrm{Se}$, As, Al, Fe, Zn). In summary, the $<63 \mu \mathrm{m}$ sediment sub-samples were each placed in $50 \mathrm{~mL}$ Teflon centrifuge tubes, with the residue from each extraction being used as the stock for the subsequent extraction. Constant agitation was achieved by placing samples into an incubator-shaker (TSSWB15 Shaking Water Bath, Thomas Scientific, Columbia, MD, USA) at $150 \mathrm{rpm}$ and $25{ }^{\circ} \mathrm{C}$. After each extraction step, the sub-samples were centrifuged for $30 \mathrm{~min}$ at $10,000 \mathrm{rpm}$ and $25^{\circ} \mathrm{C}$ in a centrifuge (Sorvall RC6+, Thermo Scientific, Columbia, MD, USA) using an SS-34 rotor attachment. The supernatants were extracted, stored in $50 \mathrm{~mL}$ Falcon tubes, and diluted to $30 \mathrm{~mL}$ with $2 \% \mathrm{HNO}_{3}$ until ready for analysis. The sediments after each step were then washed with $8 \mathrm{~mL}$ DI water and agitated continuously for $5 \mathrm{~min}$ before being centrifuged for $30 \mathrm{~min}$ as described above. Wash residue supernatants 
were discarded, and the remaining residual sediments were then ready to advance to the next step in the extraction process.

All PTE concentrations are expressed in $\mathrm{mg} / \mathrm{kg}$ except for $\mathrm{Al}$, and Fe which are expressed as percentages. Of the five fractions described by Tessier et al. [22], the exchangeable (F1), acid-soluble (F2), reducible (F3), and oxidizable (F4) were analyzed. The residual (F5) fraction was not analyzed because the PTEs found in this chemical fraction will not be bioavailable since they are found within the crystalline structure of silicate minerals. Total concentration, as referred to in this article, represents the summation of all the extracted fractions (F1 + F2 + F3 + F4) of each PTE in each of the sub-samples. Prior to PTE analysis using Inductively Coupled Plasma Optical Emission Spectrometry (ICP-OES), all aliquots were filtered $(0.25 \mu \mathrm{m})$ after acidification with $2 \% \mathrm{HNO}_{3}$ to ensure and eliminate any sediment residue. For PTE concentrations that are below the detection limit of the ICP-OES $(0.001 \mathrm{mg} / \mathrm{L})$, we recorded the concentration as half of the detection limit based on Parker and Arnold's [23] recommendation. This approach rejects the potential of false zeroes and gives weight to the actual presence of the PTE. For cross-correlation, heat maps illustrating the concentration and spatial distribution were plotted for raw PTEs, mud, TOC, $\% \mathrm{CaCO}_{3}$, and the three most abundant benthic species of foraminifera using the Surfer ${ }^{\circledR}$ software ver. 22.1.151 (www.goldensoftware.com, accessed on 10 September 2021).

\subsection{Evaluation of Sediment Contamination}

The PTE spatial distribution and the level of pollution could provide information that explains the distribution and diversity of foraminifera in the lagoon. To do this, single element and multi-element pollution indices were employed to assess the quality of the sediments. The single element pollution indices, which include the contamination factor $(\mathrm{CF})$ and the enrichment factor (EF), give information on the relationship of the concentration of a PTE at a given location to their corresponding background values. Because of the lack of baseline and historical PTE data in the study area, the average shale composition values as proposed by Turekian and Wedepohl [24] were employed. The $\mathrm{CF}$ is defined as the ratio between the concentrations of PTEs at sampling location and their background values $\left(\mathrm{CF}=\mathrm{C}_{\text {metal }} / \mathrm{C}_{\text {background value, }}\right.$ where $\mathrm{C}_{\text {metal }}=\mathrm{PTE}$ concentration in the sample, and $\mathrm{C}_{\text {background value }}=$ PTE background value in shale). Four levels of contamination are associated with $\mathrm{CF}$, ranging from un- to highly polluted (Table 1).

Similarly, the EF for all PTEs were also determined by comparing the concentration of individual PTEs relative to a reference concentration. This EF provides information on possible sources, i.e., crustal/geogenic/lithologic or anthropogenic in a given sample. In this study, $\mathrm{Al}$ was used as the normalization element because it is considered not to have an anthropogenic origin in the lagoon $[25,26]$. The EF was calculated according to the following equation:

$$
\mathrm{EF}=\frac{\left(\frac{C_{i}}{C_{r e f}}\right) \text { Sample }}{\left(\frac{C_{i}}{C_{r e f}}\right) \text { Crust }}
$$

where $C_{i}$ is the concentration of the PTE of interest and $C_{\text {ref }}$ is the concentration of the normalization element $(\mathrm{Al})$. Generally, five contamination categories are associated with EF (Table 1).

The ecological Risk Index (RI) is a multi-elemental pollution index of a sample location that considers the cumulative Ecological risk factors (Er) of PTEs in a given sediment sample (Table 1). The Er was calculated according to the following equation: $\mathrm{Er}=\operatorname{Trf} \times \mathrm{CF}$, where for a given PTE, Trf is the toxic-response factor and CF is the contamination factor [25]. 
Table 1. Thresholds for sediment quality classification for single and multi-element indices (adapted from [27]).

\begin{tabular}{cccc}
\hline Qualification & $\begin{array}{c}\text { Contamination } \\
\text { Factor }\end{array}$ & Enrichment Factor & $\begin{array}{c}\text { Ecological Risk } \\
\text { Index }\end{array}$ \\
\hline Unpolluted/Slightly & $\mathrm{CF}<1$ & $\mathrm{EF}<2$ & $<150($ low $)$ \\
Moderately & $1<\mathrm{CF}<3$ & $2<\mathrm{EF}<5$ & $150<\mathrm{RI}<300$ \\
(moderate) \\
Severely & $3<\mathrm{CF}<6$ & $5<\mathrm{EF}<20$ & $300<\mathrm{RI}<600$ \\
High & $\mathrm{CF}>6$ & $20<\mathrm{EF}<40$ & $\mathrm{RI}>600$ (very high) \\
Extreme & - & $\mathrm{EF}>40$ & - \\
\hline
\end{tabular}

\subsection{Multivariate Analyses}

Cluster analyses (CA) were carried out using the 13 most frequent and abundant benthic foraminifera (representing $98.3 \%$ of the total population). The focus on the 13 most abundant taxa reduces background noise and reveals the underlying signatures of the assemblages [13]. The paired group algorithm using the Bray Curtis matrix was applied to generate R- and Q-mode clusters. Cluster and principal component analyses (PCA), as well as numerical and statistical grain-size analyses involving ternary plot, were computed using the Paleontological Statistics Software Package for Education and Data Analysis (PAST 3.13; [28]).

For cross-correlation and assessment of the significance of individual factors, a Pearson correlation matrix was calculated by (i) using the log-transformation of TOC, \%mud, $\% \mathrm{CaCO}_{3}, \mathrm{~S}, \mathrm{D}, \mathrm{H}(\mathrm{S})$, foraminiferal number $(\mathrm{FN})$, wall texture (\% hyaline, $\%$ porcelaneous, $\%$ agglutinated), total and F1-F4 PTE concentrations and (ii) for the remaining 10 bioavailable PTEs, including the three most abundant species of benthic foraminifera (Ammonia aoteana, Ammotium salsum, and Trochammina sp. 1).

\section{Results}

\subsection{Lagos Lagoon Water Characteristics}

Due to the limited exchange with marine waters, the Lagos Lagoon system experiences restricted marine and mainly low salinity, brackish and freshwater conditions [13]. In general, the western sector of the lagoon experiences higher salinity because of its interactions with the Atlantic Ocean (16-34\%). Towards the northern and eastern portions of the lagoon, low salinity $(0-10 \%)$ and freshwater conditions are predominant for most of the year. Towards the middle and southwestern portions of the lagoon (e.g., Commodore Channel) the range in salinities fluctuates between $10-16 \%$ in the wet season and from $16-34 \%$ during the dry season. Surface water $\mathrm{pH}$ values are low and range from 5.8-6.9. The surface water temperature varies between $24.1-29.8^{\circ} \mathrm{C}$ with a decreasing SW to NE trend.

\subsection{Sediment Texture and Characteristics}

The TOC values range from $0.32-21.63 \%$. An overall $65-$ fold increase is observed in a SW (estuarine mouth) to NE trend (Figure 2; Table 2), with $35 \%$ of the sampled stations having TOC values $>4 \%$. The $\% \mathrm{CaCO}_{3}$ has an almost 200 -fold increase ranging from $0.44-86.16 \%$ (Figure 2; Table 2). For sediment texture, medium sand is the most abundant ( $\Phi=2 ; 44 \%$ of stations) grain size followed by coarse sand $(\Phi=1 ; 16 \%$ of stations) and mud ( $\Phi>4 ; 16 \%$ of stations) (Figure 2; Table 2). Unlike TOC, medium sand increased $20-$ fold in a NE to SW trend ranging from $2.2-44.13 \%$, with $54 \%$ of the sample stations with values $>20 \%$. A ternary diagram (Figure 3 ) shows the relationship between the sediment texture and TOC. Many stations in the eastern part of the lagoon revealed that TOC $>4 \%$ are associated with muddy sediments while those with $<4 \%$ are associated with sandy sediments in the western and central parts of the lagoon. 


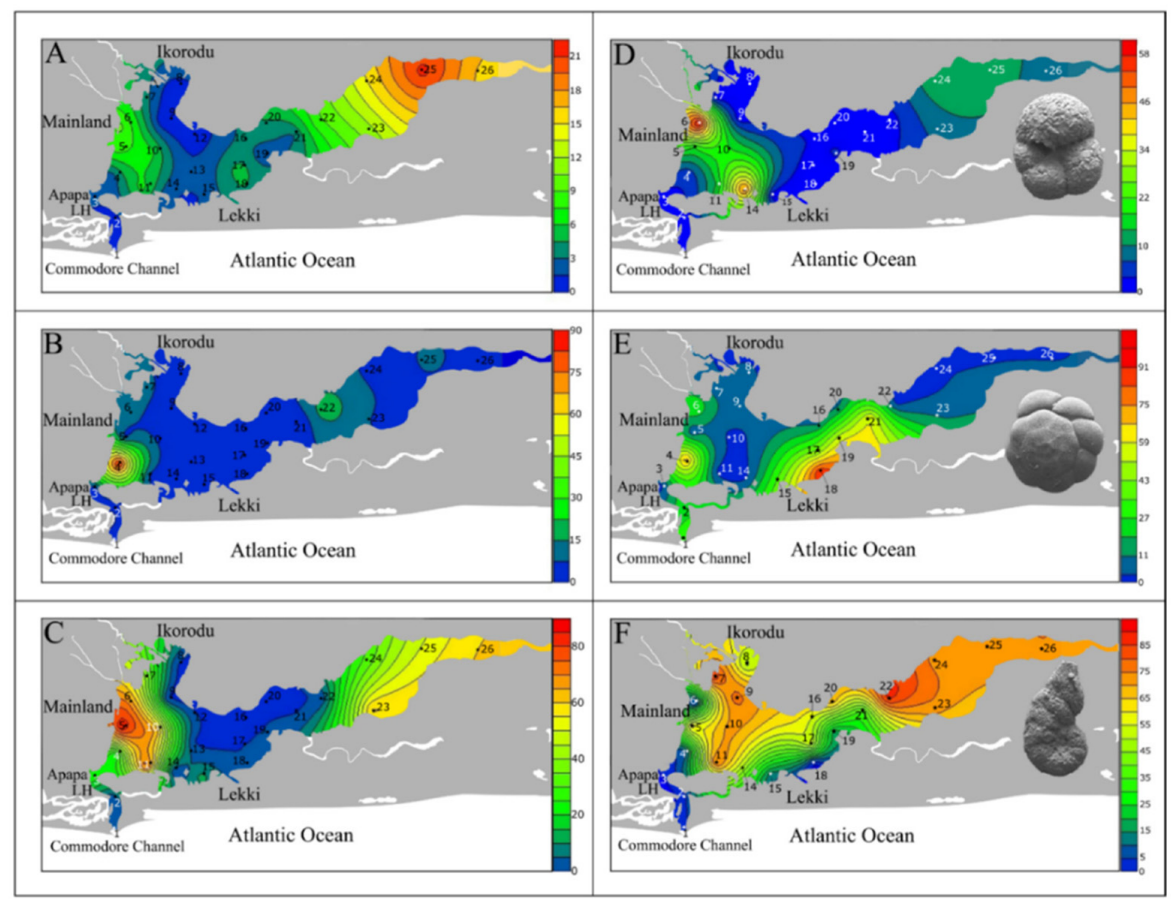

Figure 2. Spatial distribution and \% concentration of (A) Total organic carbon (\%), (B) Carbonate (\%), (C) mud (silt + clay) (\%) and percent abundances of the three most abundant species of foraminifera; (D) Trochammina sp.1, (E) Ammonia aoteana and (F) Ammotium salsum in the Lagos Lagoon. LH (Lagos Harbour).

Table 2. Sediment and water characteristics in the Lagos lagoon in May 2019: Depth (m), $\mathrm{pH}$, Temperature $\left({ }^{\circ} \mathrm{C}\right)$, Total Organic Carbon (TOC), Calcium Carbonate $\left(\% \mathrm{CaCO}_{3}\right)$, mud content $(\%$ silt and clay), and Median Grain Size $(\Phi) ;(\mathrm{N} / \mathrm{D}=$ No Data).

\begin{tabular}{|c|c|c|c|c|c|c|c|}
\hline Station \# & Depth (m) & $\mathrm{pH}$ & Temp $\left({ }^{\circ} \mathrm{C}\right)$ & TOC (\%) & $\mathrm{CaCO}_{3}(\%)$ & Mud (\%) & $\Phi$ \\
\hline 1 & 13 & 6.9 & 29.8 & 0.86 & 2.01 & 0.18 & 2 \\
\hline 2 & 12 & 6.8 & 29.2 & 0.51 & 0.93 & 0.22 & 2 \\
\hline 3 & 13 & 6.5 & 29.1 & 2.05 & 3.87 & 22.96 & 2 \\
\hline 4 & 10 & 6.4 & 29.0 & 1.94 & 86.16 & 20.55 & 2 \\
\hline 5 & 5 & 6.9 & 29.2 & 7.91 & 6.31 & 84.53 & $>4$ \\
\hline 6 & 7.5 & 6.6 & 29.2 & 9.38 & 10.90 & 72.38 & $>4$ \\
\hline 7 & 3 & 6.6 & 27.5 & 4.79 & 10.01 & 44.51 & 4 \\
\hline 8 & 4 & 6.5 & 27.3 & 0.76 & 2.27 & 0.00 & 1 \\
\hline 9 & 6 & 6.5 & 26.2 & 0.32 & 2.96 & 0.17 & 1 \\
\hline 10 & 7 & 6.6 & 27.8 & 6.31 & 5.76 & 63.27 & $>4$ \\
\hline 11 & 7 & 6.4 & 27.7 & 6.55 & 6.17 & 74.75 & $>4$ \\
\hline 12 & 3 & 6.7 & 26.8 & 0.43 & 0.44 & 0 & 3 \\
\hline 13 & 4 & 6.8 & 26.7 & 1.68 & 0.55 & 0 & 3 \\
\hline 14 & 12 & 6.5 & 27.7 & 1.78 & 1.60 & 0.22 & 2 \\
\hline 15 & 12 & 5.8 & 26.3 & 1.38 & 1.50 & 12 & 2 \\
\hline 16 & 5 & 6.8 & 25.9 & 3.25 & 2.85 & 0 & 1 \\
\hline 17 & 4 & 6.7 & 25.1 & 5.25 & 6.23 & 0.12 & 2 \\
\hline 18 & 3 & 6.8 & 24.5 & 4.46 & 6.07 & 0.16 & 1 \\
\hline 19 & 4 & 6.7 & 24.9 & 2.18 & 6.43 & 0.18 & 2 \\
\hline 20 & 3 & 6.8 & 24.1 & 4.44 & 3.01 & 0 & 2 \\
\hline 21 & 3 & 6.6 & 24.2 & 2.74 & 1.16 & 0 & 2 \\
\hline 22 & 3 & 6.8 & 25.1 & 8.52 & 20.32 & 1.74 & 2 \\
\hline 23 & 4 & 6.6 & 24.3 & 11.09 & 6.88 & 60.47 & 4 \\
\hline 24 & 2 & 6.5 & 24.3 & 14.79 & 5.03 & 32.69 & 3 \\
\hline 25 & 3 & 6.8 & 24.5 & 21.63 & 8.24 & \multicolumn{2}{|c|}{$\mathrm{N} / \mathrm{D}$} \\
\hline 26 & 5 & 6.7 & 24.2 & 16.05 & 5.69 & 60.78 & 4 \\
\hline
\end{tabular}




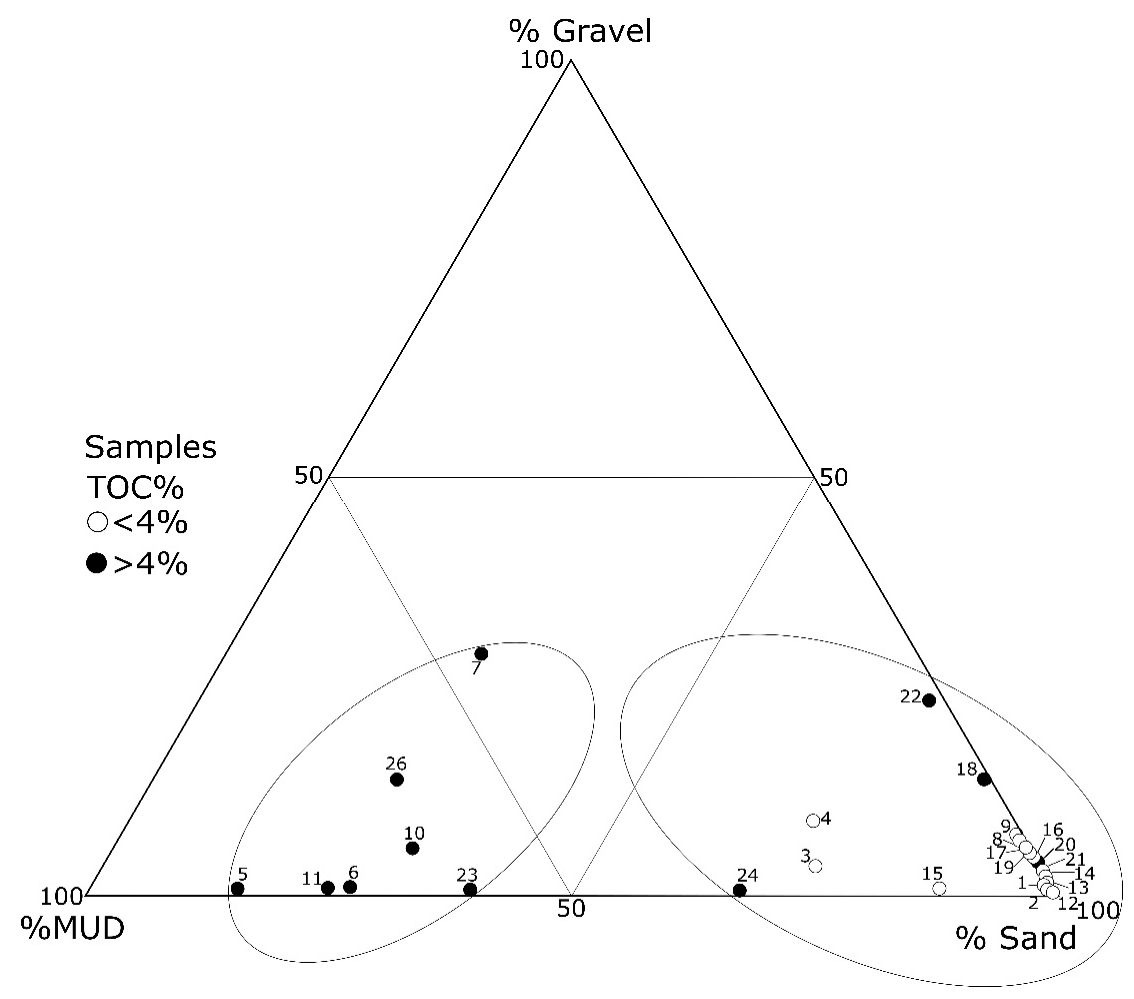

Figure 3. Ternary diagram of grain-size analysis distribution and organic matter content (TOC).

\subsection{Spatial Distribution of Foraminiferal Assemblages}

Q-mode cluster analysis revealed that foraminiferal assemblages recorded across the lagoon exhibit a two-part pattern that is separated along the lines of wall structural types (Figure 4). The clusters occupy different sectors of Lagos Lagoon, and their spatial separation was found to be largely driven by salinity (see [13]). Agglutinated foraminifera strongly dominate in the low saline eastern and northwestern portions of the lagoon and foraminifera with a hyaline-perforate or porcelaneous test are mainly present in the marine-influenced areas. Cluster Q1 (including subclusters I, II, and III) is dominated by agglutinated taxa (Ammotium, Trochammina, and Ammobaculites) and contains those samples sites with TOC $>4 \%$, while samples with TOC $<4 \%$ and dominated by hyaline-perforate species (Ammonia) are clustered in Q2 (Figure 4).

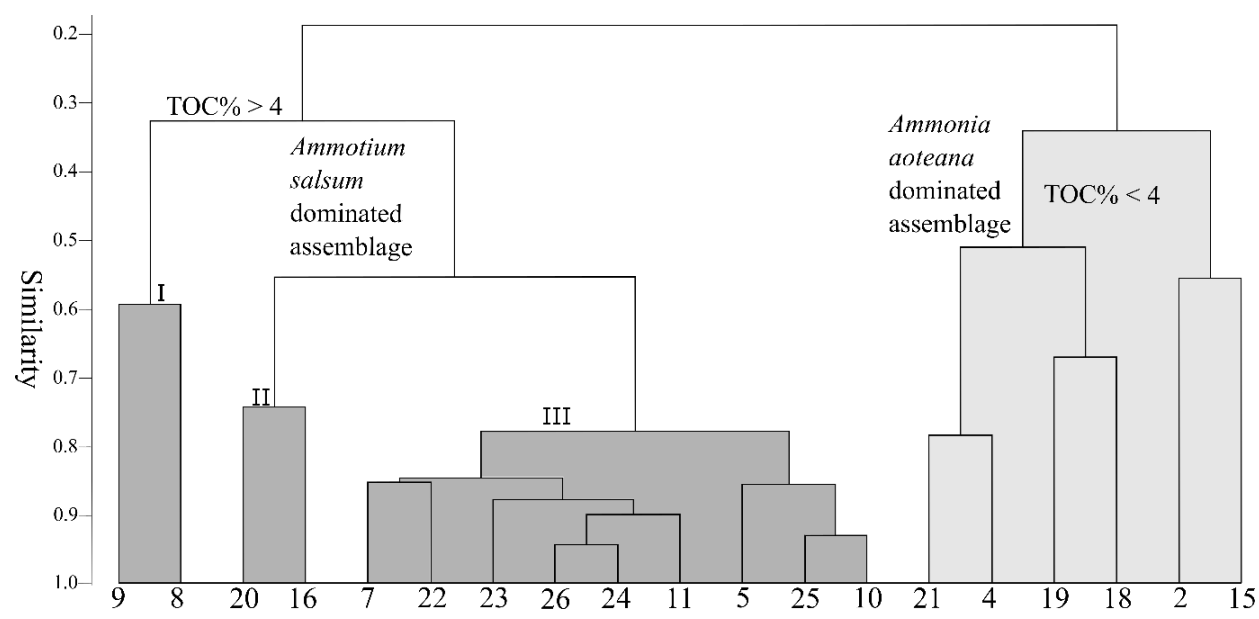

Figure 4. Cluster analysis dendrograms (Bray Curtis coefficient matrix). Q-mode: Q1 = TOC $>4 \%$ and Q2 $=$ TOC $<4 \%$ (modified after [13]). 


\subsection{Potentially Toxic Elements (PTEs)}

A total of 11 PTEs (Cr, Co, Cu, Ni, Cd, Pb, Se, As, Al, Fe, Zn) were analyzed in this study (see Appendix A-Table A1). Some PTEs were found to be below the detection limit in certain sediment chemical fractions and were not used in the statistical analysis. These include $\mathrm{Cr}$, $\mathrm{Ni}$, and $\mathrm{Pb}$ in the F1 fraction and $\mathrm{Se}$ in the F4 fraction. Cd and As were completely excluded from this study due to having concentrations below the detection limits in almost all the sampled stations. All of the total PTE concentrations cross-correlate positively amongst themselves except for $\mathrm{Cr}-\mathrm{Cu}$ and $\mathrm{Cr}-\mathrm{Al}$ pairs, which have no significant correlations at the $95 \%$ confidence interval. Selenium negatively cross-correlates with the rest of the PTEs. All the PTEs have relative even distributions related to their total concentrations with the following range values: Cr (2.34-96.42 mg/kg), Co (0.38-16.02 mg/kg), Cu (1.11-130.32 mg/kg), Ni (0.51-13.58 mg/kg), Pb (3.51-916.47 mg/kg), Se (31.82-120.92 mg/kg), Al (0.02-0.31\%), Fe (0.11-2.20\%), and Zn (11.07-183.63 mg/kg) (Figure 5A-I). The highest concentrations for $\mathrm{Cr}$, $\mathrm{Cu}, \mathrm{Ni}$, and $\mathrm{Zn}$ were found towards the west of the lagoon.

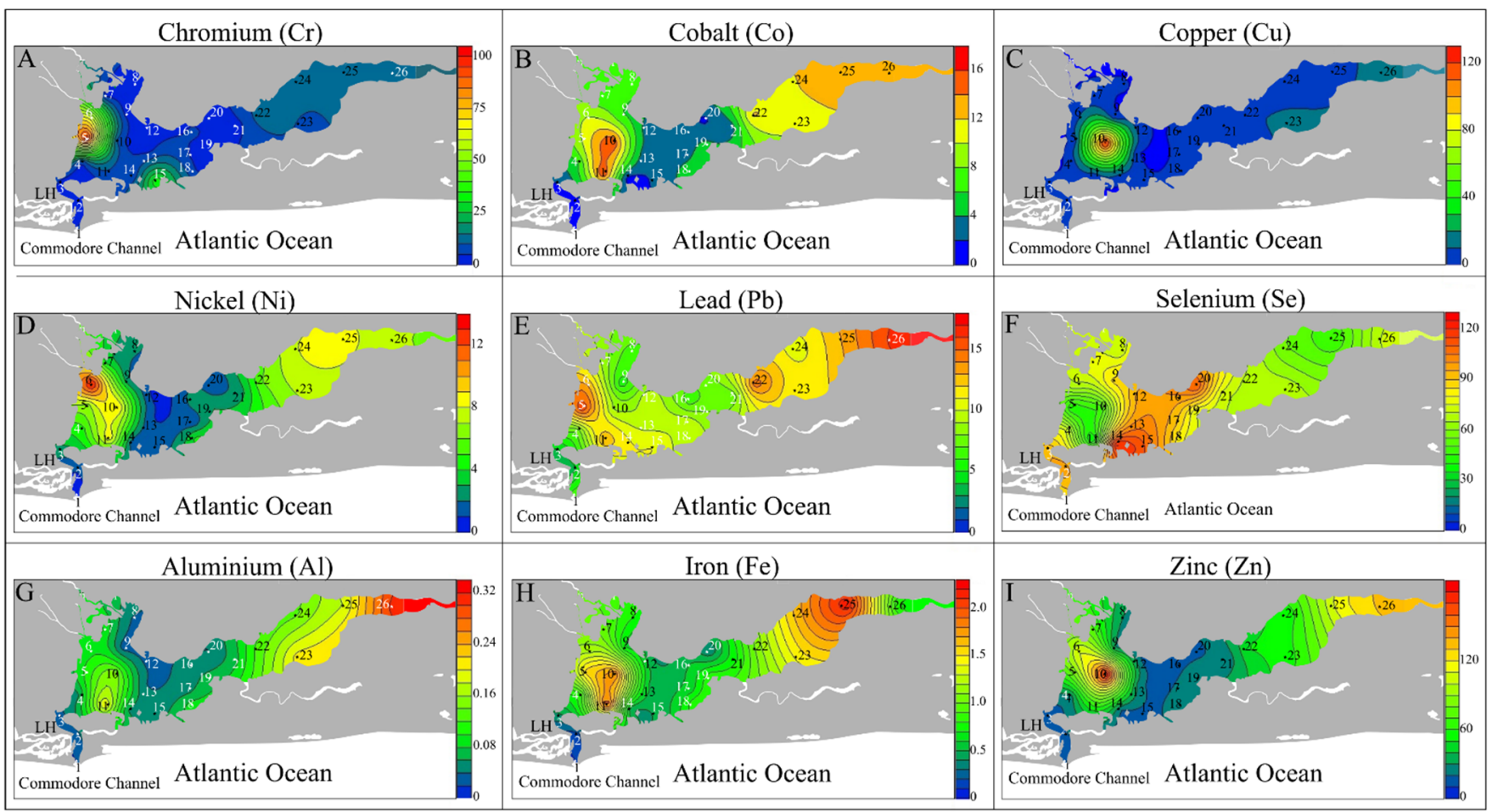

Figure 5. Heat maps showing the spatial distribution and total concentration of PTEs across the Lagos Lagoon. (A) Chromium (Cr), (B) Cobalt (Co), (C) Copper (Cu), (D) Nickel (Ni), (E) Lead (Pb), (F) Selenium (Se), (G) Aluminum (Al), (H) Iron (Fe), (I) Zinc (Zn). All concentrations are in mg/kg except for $\mathrm{Al}$ and Fe which are in percent. LH (Lagos Harbour).

The percent recovery of each PTE across the sequential fractions is illustrated in Figure 6; while their actual concentrations are provided in Appendix A (Table A1). Most PTEs were found dominant in the F3 fraction except for $\mathrm{Cu}$ and $\mathrm{Al}$, which dominate the F4 fraction, respectively. The spatial distribution maps of the bioavailable PTE fractions (F1-F4) are shown in Appendix B (Figures A1-A4). For Cr, the following concentrations (mg/kg) were found in each fraction: $0.06-0.21\left(\mathrm{Cr}_{\mathrm{F} 2}\right), 1.5-93\left(\mathrm{Cr}_{\mathrm{F} 3}\right)$, and 0.48-7.23 $\left(\mathrm{Cr}_{\mathrm{F} 4}\right)$. For Co, the following concentrations $(\mathrm{mg} / \mathrm{kg})$ were found in each fraction: 0-0.39 (Co $\left.\mathrm{F}_{1}\right), 0-1.47\left(\mathrm{Co}_{\mathrm{F} 2}\right)$, 0.3-10.2 ( $\left.\mathrm{Co}_{\mathrm{F} 3}\right)$, and 0-4.38 ( $\left.\mathrm{Co}_{\mathrm{F} 4}\right)$. The $\mathrm{Cu}_{\mathrm{F} 1}$ through $\mathrm{Cu}_{\mathrm{F} 4}$ concentrations $(\mathrm{mg} / \mathrm{kg})$ ranged from $0.06-3,0-0.24,0-3.9$, and 0.18-129.51 respectively. For $\mathrm{Ni}$, the following concentrations $(\mathrm{mg} / \mathrm{kg})$ were found in each fraction: $0-0.33\left(\mathrm{Ni}_{\mathrm{F} 2}\right), 0.30-11.4\left(\mathrm{Ni}_{\mathrm{F} 3}\right)$, and $0.12-3.36\left(\mathrm{Ni}_{\mathrm{F} 4}\right)$. In the case of $\mathrm{Pb}$, the concentrations $(\mathrm{mg} / \mathrm{kg})$ ranged from $0.27-3.18(\mathrm{~Pb} / \mathrm{F} 2), 1.80-15.6\left(\mathrm{~Pb}_{\mathrm{F} 3}\right)$, and 0.02-0.96 $\left(\mathrm{Pb}_{\mathrm{F} 4}\right)$. For $\mathrm{Se}$, the following concentrations $(\mathrm{mg} / \mathrm{kg})$ were found in each fraction: 
0-0.57 $\left(\mathrm{Se}_{\mathrm{F} 1}\right), 0.9-19.8\left(\mathrm{Se}_{\mathrm{F} 2}\right)$, and 30-111.3 $\left(\mathrm{Se}_{\mathrm{F} 3}\right)$. For the $\mathrm{Al}_{\mathrm{F} 1}$ through $\mathrm{Al}_{\mathrm{F} 4}$ chemical fractions, the $\mathrm{Al}$ values ranged $(\%)$ from $6.3 \times 10^{-5}-3.88 \times 10^{-3}, 9.9 \times 10^{-5}-7.53 \times 10^{-4}, 0.01-0.04$, and $4 \times 10^{-3}-0.28$ respectively. For Fe, the following values $(\%)$ were found in each fraction: $1.4 \times 10^{-4}-7.6 \times 10^{-3}\left(\mathrm{Fe}_{\mathrm{F} 1}\right), 2.9 \times 10^{-4}-7.4 \times 10^{-3}\left(\mathrm{Fe}_{\mathrm{F} 2}\right), 0.1-1.62\left(\mathrm{Fe}_{\mathrm{F} 3}\right)$, and $5.4 \times 10^{-3}$ $0.73\left(\mathrm{Fe}_{\mathrm{F} 4}\right)$. Finally, for $\mathrm{Zn}$, the following concentrations $(\mathrm{mg} / \mathrm{kg})$ were found in each fraction: 0.06-0.87 $\left(\mathrm{Zn}_{\mathrm{F} 1}\right), 0.48-21\left(\mathrm{Zn}_{\mathrm{F} 2}\right), 9.9-103.8\left(\mathrm{Zn}_{\mathrm{F} 3}\right)$, and 0-137.31 $\left(\mathrm{Zn}_{\mathrm{F} 4}\right)$. Most of the bioavailable PTEs have the same relative even distribution as the total distribution. However, in the western and eastern sections of the lagoon, $\mathrm{Co}_{\mathrm{F} 1}, \mathrm{Ni}_{\mathrm{F} 4}$, and $\mathrm{Fe}_{\mathrm{F} 4}$ have the highest concentrations, while $\mathrm{Se}_{\mathrm{F} 3}$ and $\mathrm{Pb}_{\mathrm{F} 4}$, are found in the central part.

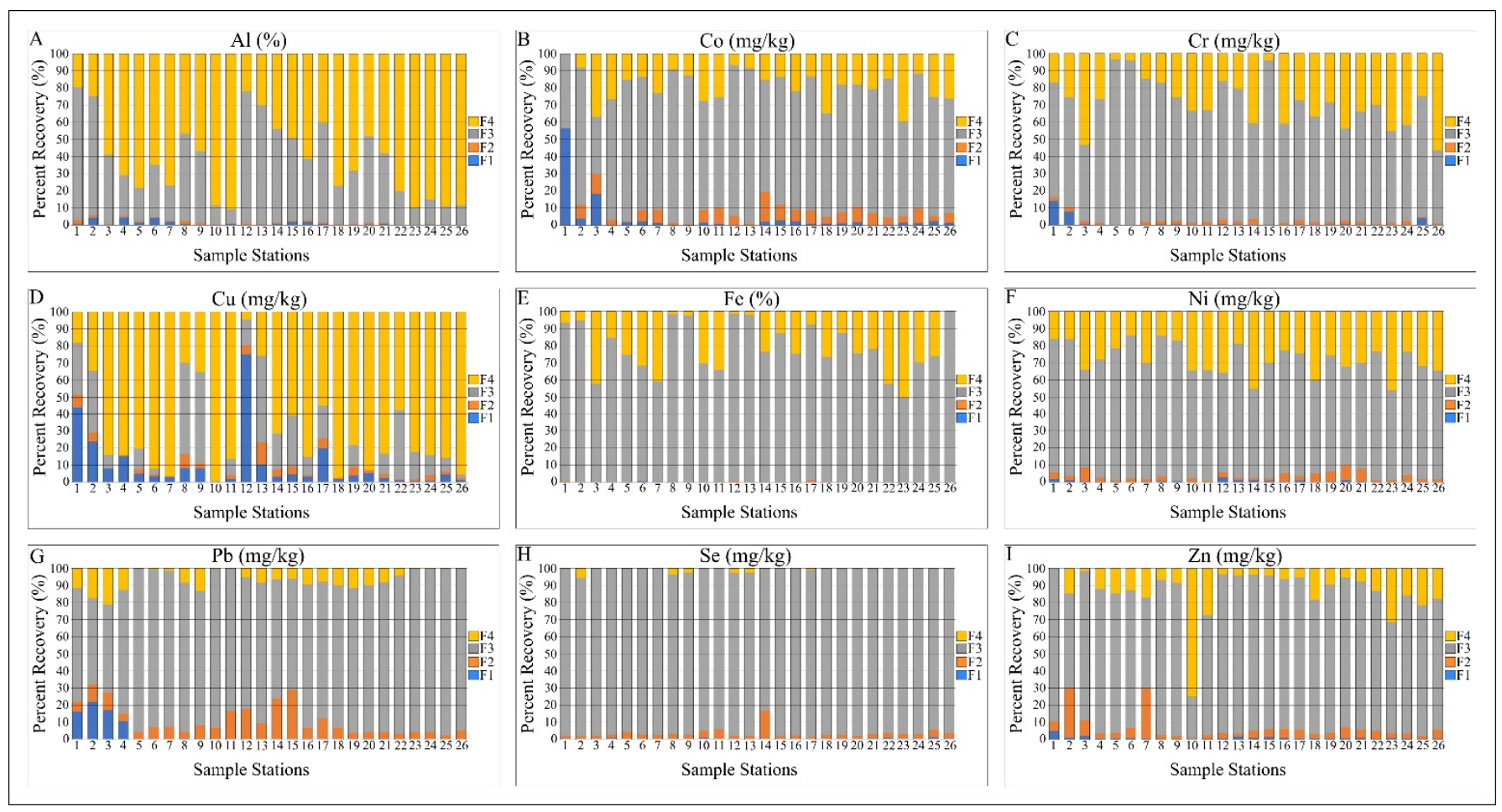

Figure 6. PTEs recovery percentage. (A) Aluminum (Al), (B) Cobalt (Co), (C) Chromium (Cr), (D) Copper (Cu), (E) Iron (Fe), (F) Nickel (Ni), (G) Lead (Pb), (H) Selenium (Se), (I) Zinc (Zn). All concentrations are in $\mathrm{mg} / \mathrm{kg}$ except for $\mathrm{Al}$, and Fe which are in (\%). F1 = exchangeable; F2 = acid-soluble; F3 = reducible; and F4 = oxidizable.

Principal component analysis (Figure 7) confirms the separation of the sample stations based on the amount of TOC in each sample $(>4 \%$ or $<4 \%)$ and on the total PTE concentrations of $\mathrm{Fe}, \mathrm{Al}, \mathrm{Zn}$, Se, and $\mathrm{Pb}$ as revealed in ellipsoids $\mathrm{A}-\mathrm{F}$. All stations with $<4 \% \mathrm{TOC}$ seem not to be affected by PTEs given their low concentrations (e.g., PCA vectors at the origin). However, the sampled stations with $>4 \%$ TOC found in the western and eastern parts of the lagoon seem to be influenced more by Fe (ST7, ST10, ST24, ST25) and Al (ST11, ST22, ST23).

\section{Correlation Matrix Analysis}

The Pearson correlation matrix (Table 3) shows that the PTE total concentrations positively correlate with mud and TOC except for Se, which correlates negatively. Similarly, most of the sequentially extracted PTEs correlate positively with mud and TOC except for $\mathrm{Pb}_{\mathrm{F} 4}$ and $\mathrm{Se}_{\mathrm{F} 3}$, which correlate negatively. Only $\mathrm{Al}_{\mathrm{F} 1}$ and $\mathrm{Fe}_{\mathrm{F} 1}$ correlate negatively with mud. The fractions $\mathrm{Cr}_{\mathrm{F} 2}, \mathrm{Cu}_{\mathrm{F} 1}-\mathrm{Cu}_{\mathrm{F} 3}, \mathrm{~Pb}_{\mathrm{F} 2}, \mathrm{Se}_{\mathrm{F} 1}-\mathrm{Se}_{\mathrm{F} 2}, \mathrm{Al}_{\mathrm{F} 2}-\mathrm{Al}_{\mathrm{F} 3}, \mathrm{Fe}_{\mathrm{F} 2}$ show no significant correlation at the $95 \%$ confidence interval with mud and TOC. Overall, most PTEs show no significant correlation with $\% \mathrm{CaCO}_{3}$ except for $\mathrm{Co}, \mathrm{Ni}, \mathrm{Fe}$, and $\mathrm{Zn}$, whose total concentra- 
tions correlated positively. Similarly, $\mathrm{Cr}_{\mathrm{F} 4}-\mathrm{Co}_{\mathrm{F} 3-\mathrm{F} 4}-\mathrm{Ni}_{\mathrm{F} 3-\mathrm{F} 4}-\mathrm{Al}_{\mathrm{F} 1}-\mathrm{Fe}_{\mathrm{F} 3-\mathrm{F} 4}-\mathrm{Zn}_{\mathrm{F} 3-\mathrm{F} 4-\text { total }}$ have a positive correlation with $\% \mathrm{CaCO}_{3}$.

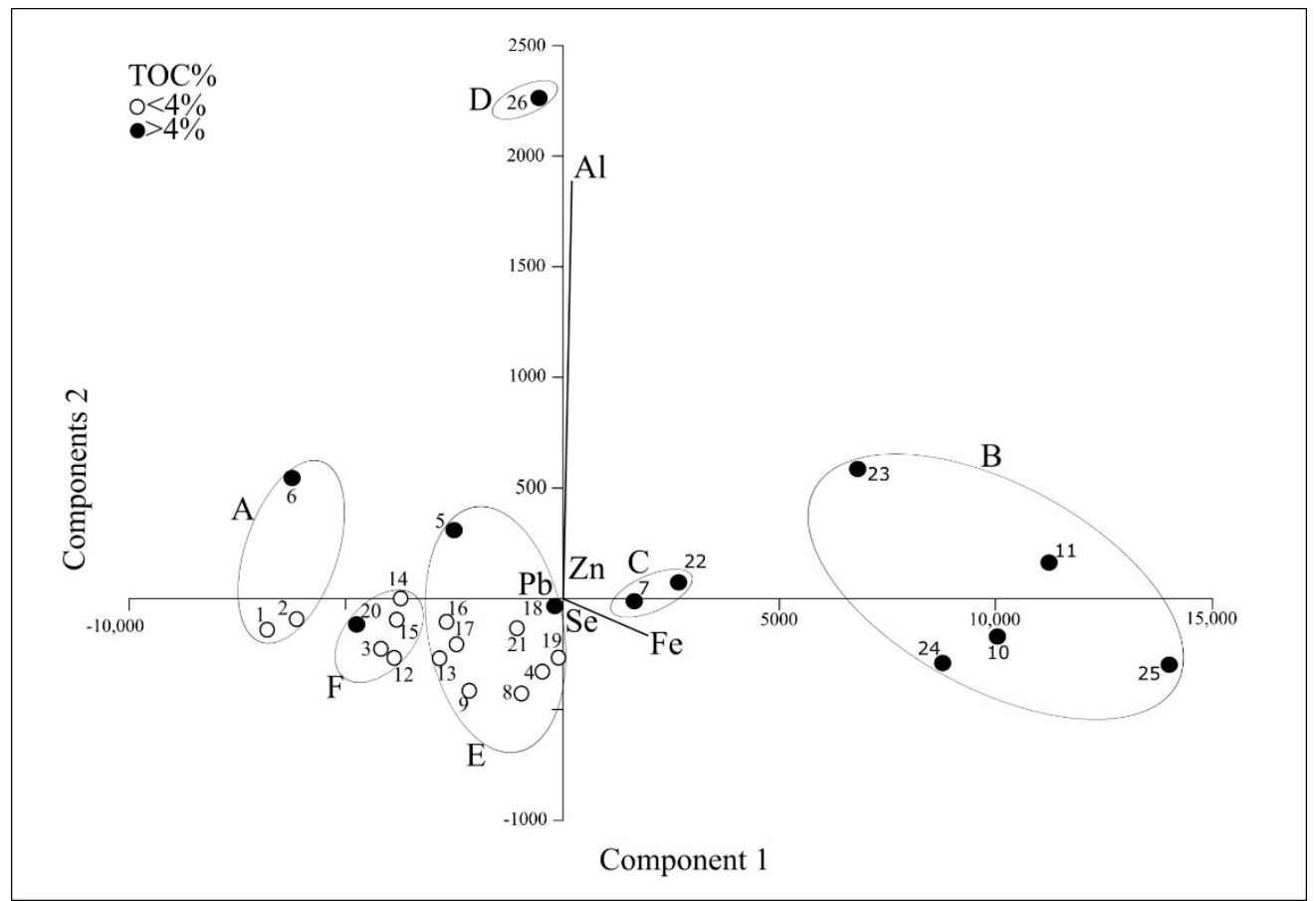

Figure 7. Principal components showing the dominance of PTEs with respect to TOC percentages. Ellipsoids A-F show sample stations with similar concentrations of TOC and dominant PTEs.

Among the three most abundant species in Lagos lagoon, A. salsum, and Trochammina sp. 1 positively correlate with mud and TOC. In addition, $A$. salsum correlates positively with $\mathrm{Cr}_{\mathrm{F} 4}$-CO-F2-F3-F4-total $-\mathrm{Cu}_{\mathrm{F} 3 \text {-F4-total }}-\mathrm{Ni}_{\mathrm{F} 3-\mathrm{F} 4 \text {-total }}-\mathrm{Pb}_{\mathrm{F} 3 \text {-total }}-\mathrm{Al}_{\mathrm{F} 4 \text {-total }}-\mathrm{Fe}_{\mathrm{F} 3-\mathrm{F} 4 \text {-total }}$ and negatively with the $\mathrm{Pb}_{\mathrm{F} 4}-\mathrm{Se}_{\mathrm{F} 3 \text {-total }}$. For Trochammina sp. 1, the following significant correlations were recorded: (1) positively with $\mathrm{Cr}_{\mathrm{F} 2-\mathrm{F} 3-\mathrm{F} 4-\text { total }}-\mathrm{Co}_{\mathrm{F} 1-\mathrm{F} 2-\mathrm{F} 3-\mathrm{F} 4-\text { total }}-\mathrm{Cu}_{\mathrm{F} 2-\mathrm{F} 4-\text { total }}-\mathrm{Ni}_{\mathrm{F} 3-\mathrm{F} 4-\text { total }^{-}}$ $\mathrm{Pb}_{\mathrm{F} 3 \text {-total }}-\mathrm{Al}_{\mathrm{F} 2-\mathrm{F} 4 \text {-total }}-\mathrm{Fe}_{\mathrm{F} 3-\mathrm{F} 4-\text { total }}-\mathrm{Zn}_{\mathrm{F} 3-\mathrm{F} 4 \text {-total }}$; and (2) negatively with the $\mathrm{Pb}_{\mathrm{F} 4}$ and with $\mathrm{Se}_{\mathrm{F} 3 \text {-total }}$. The only correlation observed with $A$. aoteana is a negative one with Cof . No significant correlation is observed between species richness $(S)$ and the PTEs coupled with TOC and $\% \mathrm{CaCO}_{3}$. Similarly, $\mathrm{H}(\mathrm{S})$ show no correlation with PTEs except negatively with $\mathrm{Co}_{\mathrm{F} 2-\mathrm{F} 4 \text {-total }}-\mathrm{Ni}_{\mathrm{F} 4 \text {-total }}-\mathrm{Pb}_{\mathrm{F} 3 \text {-total }}-\mathrm{Fe}_{\mathrm{F} 3-\mathrm{F} 4 \text {-total }}-\mathrm{Zn}_{\mathrm{F} 3 \text {-total }}$ and with TOC. On the other hand,

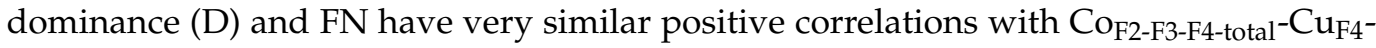
$\mathrm{Ni}_{\mathrm{F} 3-\mathrm{F} 4 \text {-total }}-\mathrm{Pb}_{\mathrm{F} 3 \text {-total }}-\mathrm{Al}_{\mathrm{F} 4 \text {-total }}-\mathrm{Fe}_{\mathrm{F} 3-\mathrm{F} 4 \text {-total }}-\mathrm{Zn}_{\mathrm{F} 3-\mathrm{F} 4 \text {-total }}$ and $\mathrm{TOC}$ while negatively with $\mathrm{Cu}_{\mathrm{F} 1}$ in the case of $\mathrm{D}$ and with $\mathrm{Pb}_{\mathrm{F} 4}-\mathrm{Se}_{\mathrm{F} 3 \text {-total }}$ regarding $\mathrm{FN}$.

Based on wall texture, the percentage of agglutinated foraminifera (AGL) correlates positively with TOC, D, FN, and A. Similar to the agglutinated species A. salsum, the AGL also correlates positively with the $\mathrm{Cr}_{\mathrm{F} 4}-\mathrm{Co}_{\mathrm{F} 1-\mathrm{F} 2-\mathrm{F} 3-\mathrm{F} 4 \text {-total }}-\mathrm{Cu}_{\mathrm{F} 2 \text {-total }}-\mathrm{PB}_{\mathrm{F} 3 \text {-total }}-\mathrm{Al}_{\mathrm{F} 4 \text {-total }}{ }^{-}$ $\mathrm{Fe}_{\mathrm{F} 3-\mathrm{F} 4-\text { total }}-\mathrm{Zn}_{\mathrm{F} 3-\mathrm{F} 4-\text { total }}$ and negatively with $\mathrm{Pb}_{\mathrm{F} 4}-\mathrm{Se}_{\mathrm{F} 3 \text {-total }}$. The percentage of porcelaneous species (P) correlates positively with $\mathrm{S}-\mathrm{H}(\mathrm{S})$ and negatively with $\mathrm{TOC}-\mathrm{CaCO}_{3}-\mathrm{D}$. However, given the very small number of porcelaneous individuals per sample (1-14), the correlations found with PTEs are considered false positives/negatives. The percentage of hyaline taxa (HP) correlates negatively with TOC and FN. Unlike A. aoetana, however, the HP mostly correlates negatively with $\mathrm{Cr}_{\mathrm{F} 4}-\mathrm{Co}_{\mathrm{F} 1-\mathrm{F} 2-\mathrm{F} 3-\mathrm{F} 4-\text { total }}-\mathrm{Cu}_{\mathrm{F} 2-\mathrm{F} 3-\text { total }}-\mathrm{Pb}_{\mathrm{F} 3 \text {-total }}-\mathrm{Al}_{\mathrm{F} 4 \text {-total }}-\mathrm{Fe}_{\mathrm{F} 3 \text {-total }}{ }^{-}$ $\mathrm{Zn}_{\mathrm{F} 3 \text {-total }}$ and positively with $\mathrm{Pb}_{\mathrm{F} 4}$ and $\mathrm{Se}_{\mathrm{F} 3 \text {-total }}$. 
Table 3. Pearson correlation matrix of PTEs of interest (F1-F4 fractions), total organic matter (\%TOC), mud (\%mud), species richness (S), dominance (D), Shannon $[\mathrm{H}(\mathrm{S})]$, foraminiferal number (FN), $\mathrm{A}=$ Ammonia aoteana $; \mathrm{B}=$ Ammotium salsum $; \mathrm{C}=$ Trochammina , and percent abundances of agglutinated (AGL), porcelaneous $(\mathrm{P})$, and hyaline-perforate $(\mathrm{HP})$ benthic foraminifera $(n=26$; grey = significant positive correlation; red = significant negative correlation; black = correlation not considered; $p<0.05[0.40])$.

\begin{tabular}{|c|c|c|c|c|c|c|c|c|c|c|c|c|c|}
\hline PTES & $S$ & D & $\mathbf{H}(\mathbf{S})$ & FN & A & B & C & AGL & $\mathbf{P}$ & HP & $\%$ TOC & $\% \mathrm{CaCO}_{3}$ & $\%$ Mud \\
\hline $\mathrm{Cr}_{\mathrm{F} 2}$ & -0.07 & -0.03 & 0.00 & 0.16 & -0.30 & 0.28 & 0.52 & 0.33 & & -0.36 & 0.27 & -0.13 & 0.33 \\
\hline $\mathrm{Cr}_{\mathrm{F} 3}$ & 0.11 & -0.01 & 0.04 & 0.23 & -0.15 & 0.17 & 0.41 & 0.21 & & -0.17 & 0.42 & 0.26 & 0.57 \\
\hline $\mathrm{Cr}_{\mathrm{F} 4}$ & -0.11 & 0.38 & -0.33 & 0.55 & -0.17 & 0.66 & 0.69 & 0.40 & & -0.41 & 0.82 & 0.40 & 0.62 \\
\hline Crtotal & 0.08 & 0.03 & 0.00 & 0.27 & -0.17 & 0.25 & 0.49 & 0.24 & & -0.21 & 0.52 & 0.29 & 0.63 \\
\hline $\mathrm{Co}_{\mathrm{F} 1}$ & -0.13 & -0.06 & 0.00 & 0.08 & -0.41 & 0.23 & 0.47 & 0.12 & & -0.13 & 0.47 & 0.17 & 0.58 \\
\hline CoF2 & -0.27 & 0.46 & -0.44 & 0.60 & -0.25 & 0.63 & 0.69 & 0.46 & & -0.47 & 0.66 & 0.36 & 0.65 \\
\hline $\mathrm{Co}_{\mathrm{F} 3}$ & -0.20 & 0.62 & -0.51 & 0.77 & -0.16 & 0.68 & 0.68 & 0.61 & & -0.59 & 0.66 & 0.51 & 0.57 \\
\hline $\mathrm{CO}_{\mathrm{F} 4}$ & -0.21 & 0.64 & -0.53 & 0.75 & -0.05 & 0.71 & 0.74 & 0.42 & & -0.43 & 0.75 & 0.58 & 0.74 \\
\hline Cototal & -0.25 & 0.65 & -0.56 & 0.77 & -0.14 & 0.70 & 0.71 & 0.58 & & -0.56 & 0.72 & 0.56 & 0.65 \\
\hline $\mathrm{Cu}_{\mathrm{F} 1}$ & 0.04 & -0.40 & 0.31 & -0.35 & -0.08 & -0.33 & -0.13 & -0.29 & & 0.28 & -0.33 & -0.24 & -0.17 \\
\hline $\mathrm{Cu}_{\mathrm{F} 2}$ & -0.03 & -0.10 & 0.08 & 0.29 & -0.34 & 0.34 & 0.65 & 0.44 & & -0.44 & 0.23 & -0.30 & 0.17 \\
\hline $\mathrm{Cu}_{\mathrm{F} 3}$ & 0.15 & 0.08 & -0.03 & 0.33 & -0.33 & 0.45 & 0.21 & 0.39 & & -0.42 & 0.19 & 0.02 & 0.06 \\
\hline $\mathrm{Cu}_{\mathrm{F} 4}$ & -0.16 & 0.43 & -0.38 & 0.59 & -0.16 & 0.60 & 0.68 & 0.37 & & -0.39 & 0.71 & 0.41 & 0.71 \\
\hline Cutotal & -0.12 & 0.37 & -0.33 & 0.58 & -0.23 & 0.61 & 0.68 & 0.40 & & -0.42 & 0.62 & 0.31 & 0.66 \\
\hline $\mathrm{Ni}_{\mathrm{F} 2}$ & -0.24 & 0.18 & -0.21 & 0.14 & 0.19 & 0.09 & 0.32 & -0.15 & & 0.19 & 0.52 & 0.33 & 0.37 \\
\hline $\mathrm{Ni}_{\mathrm{F} 3}$ & -0.16 & 0.47 & -0.39 & 0.65 & -0.09 & 0.58 & 0.71 & 0.39 & & -0.37 & 0.76 & 0.63 & 0.76 \\
\hline $\mathrm{Ni}_{\mathrm{F} 4}$ & -0.22 & 0.58 & -0.50 & 0.69 & -0.01 & 0.70 & 0.77 & 0.34 & & -0.35 & 0.82 & 0.57 & 0.79 \\
\hline Nitotal & -0.19 & 0.53 & -0.45 & 0.68 & -0.04 & 0.61 & 0.73 & 0.36 & & -0.35 & 0.80 & 0.64 & 0.78 \\
\hline $\mathrm{Pb}_{\mathrm{F} 2}$ & -0.19 & -0.03 & -0.08 & -0.13 & -0.27 & -0.08 & 0.08 & 0.15 & & -0.16 & -0.10 & -0.27 & 0.13 \\
\hline $\mathrm{Pb}_{\mathrm{F} 3}$ & -0.19 & 0.56 & -0.48 & 0.68 & -0.15 & 0.63 & 0.56 & 0.65 & & -0.60 & 0.75 & 0.32 & 0.45 \\
\hline $\mathrm{Pb}_{\mathrm{F} 4}$ & -0.01 & -0.28 & 0.18 & -0.69 & 0.35 & -0.74 & -0.85 & -0.61 & & 0.63 & -0.72 & -0.19 & -0.82 \\
\hline Pbtotal & -0.21 & 0.48 & -0.44 & 0.58 & -0.18 & 0.54 & 0.52 & 0.58 & & -0.54 & 0.68 & 0.28 & 0.44 \\
\hline $\mathrm{Se}_{\mathrm{F} 1}$ & 0.21 & -0.08 & 0.12 & 0.13 & 0.23 & 0.08 & -0.09 & -0.16 & & 0.09 & 0.07 & 0.23 & -0.09 \\
\hline $\mathrm{Se}_{\mathrm{F} 2}$ & -0.27 & 0.07 & -0.17 & -0.22 & -0.15 & -0.12 & -0.11 & 0.25 & & -0.29 & -0.11 & -0.19 & -0.15 \\
\hline $\mathrm{Se}_{\mathrm{F} 3}$ & 0.06 & -0.35 & 0.29 & -0.64 & 0.12 & -0.58 & -0.84 & -0.45 & & 0.46 & -0.58 & -0.37 & -0.62 \\
\hline Setotal & 0.04 & -0.36 & 0.28 & -0.65 & 0.09 & -0.59 & -0.84 & -0.42 & & 0.42 & -0.60 & -0.40 & -0.63 \\
\hline $\mathrm{Al}_{\mathrm{F} 1}$ & 0.03 & 0.01 & 0.00 & 0.08 & 0.14 & -0.08 & 0.09 & -0.05 & & 0.07 & 0.18 & 0.46 & 0.50 \\
\hline $\mathrm{Al}_{\mathrm{F} 2}$ & 0.15 & -0.07 & 0.12 & 0.26 & 0.13 & 0.15 & 0.41 & 0.28 & & -0.27 & 0.10 & 0.06 & 0.18 \\
\hline $\mathrm{Al}_{\mathrm{F} 3}$ & -0.20 & 0.04 & -0.12 & 0.11 & -0.12 & 0.10 & 0.08 & 0.26 & & -0.22 & 0.33 & -0.26 & -0.02 \\
\hline $\mathrm{Al}_{\mathrm{F} 4}$ & -0.10 & 0.50 & -0.39 & 0.77 & -0.17 & 0.80 & 0.75 & 0.50 & & -0.52 & 0.80 & 0.37 & 0.69 \\
\hline Altotal & -0.11 & 0.49 & -0.39 & 0.77 & -0.17 & 0.79 & 0.72 & 0.51 & & -0.53 & 0.82 & 0.34 & 0.68 \\
\hline $\mathrm{Fe}_{\mathrm{F} 1}$ & -0.14 & 0.13 & -0.16 & 0.16 & -0.18 & 0.09 & 0.20 & 0.23 & & -0.19 & 0.32 & 0.25 & 0.54 \\
\hline $\mathrm{Fe}_{\mathrm{F} 2}$ & -0.29 & 0.23 & -0.30 & 0.20 & -0.11 & 0.26 & 0.48 & 0.29 & & -0.25 & 0.28 & 0.07 & 0.19 \\
\hline $\mathrm{Fe}_{\mathrm{F} 3}$ & -0.16 & 0.48 & -0.40 & 0.68 & -0.08 & 0.61 & 0.82 & 0.51 & & -0.50 & 0.69 & 0.42 & 0.63 \\
\hline $\mathrm{Fe}_{\mathrm{F} 4}$ & -0.11 & 0.54 & -0.45 & 0.77 & -0.19 & 0.82 & 0.78 & 0.50 & & -0.53 & 0.86 & 0.47 & 0.79 \\
\hline Fetotal & -0.16 & 0.54 & -0.46 & 0.73 & -0.10 & 0.69 & 0.82 & 0.53 & & -0.52 & 0.76 & 0.48 & 0.71 \\
\hline $\mathrm{Zn}_{\mathrm{F} 1}$ & 0.01 & -0.15 & 0.12 & 0.07 & -0.18 & 0.09 & 0.36 & 0.06 & & -0.04 & 0.40 & 0.03 & 0.52 \\
\hline $\mathrm{Zn}_{\mathrm{F} 2}$ & 0.03 & 0.18 & -0.12 & 0.41 & -0.24 & 0.38 & 0.13 & 0.21 & & -0.25 & 0.43 & 0.27 & 0.51 \\
\hline $\mathrm{Zn}_{\mathrm{F} 3}$ & -0.21 & 0.52 & -0.44 & 0.70 & -0.22 & 0.64 & 0.68 & 0.59 & & -0.57 & 0.80 & 0.45 & 0.69 \\
\hline $\mathrm{Zn}_{\mathrm{F} 4}$ & -0.08 & 0.49 & -0.38 & 0.76 & -0.16 & 0.68 & 0.78 & 0.48 & & -0.50 & 0.72 & 0.44 & 0.73 \\
\hline Zntotal & -0.15 & 0.49 & -0.40 & 0.74 & -0.24 & 0.68 & 0.74 & 0.57 & & -0.57 & 0.77 & 0.43 & 0.74 \\
\hline \%TOC & -0.23 & 0.55 & -0.48 & 0.67 & -0.17 & 0.72 & 0.67 & 0.48 & -0.49 & -0.46 & & & \\
\hline$\% \mathrm{CaCO}_{3}$ & -0.25 & 0.58 & -0.52 & 0.40 & 0.23 & 0.29 & 0.32 & 0.05 & -0.47 & -0.02 & & & \\
\hline$\%$ Mud & -0.08 & 0.27 & -0.22 & 0.50 & -0.15 & 0.53 & 0.73 & 0.27 & -0.31 & -0.29 & & & \\
\hline AGL & -0.06 & 0.40 & -0.30 & 0.59 & & & & & & & & & \\
\hline $\mathrm{P}$ & 0.60 & -0.74 & 0.77 & -0.33 & & & & & & & & & \\
\hline $\mathrm{HP}$ & 0.04 & -0.39 & 0.29 & -0.61 & & & & & & & & & \\
\hline
\end{tabular}

\subsection{Sediment Contamination Indices}

Based on the CF of the PTE total concentrations, six stations can be classified as "moderately" polluted for chromium (5), copper (10), and zinc $(6,10,25,26)$, and 100\% of the sampled stations are classified as "highly polluted" for selenium (Table 4 and Figure $8 \mathrm{~A}$ ). The EF show that $27 \%(\mathrm{Cr}), 46 \%(\mathrm{Ni})$, and $4 \%(\mathrm{Fe})$ of the sample sites fall in the category "moderately" polluted while 58\%, 31\%, 89\%, 54\%, and 58\% of samples are classified as "severely" polluted for $\mathrm{Cr}, \mathrm{Co}, \mathrm{Cu}, \mathrm{Ni}$, and Fe, respectively. The category of "high" pollution was represented by $4 \%(\mathrm{Cr}), 38 \%(\mathrm{Co}), 8 \%(\mathrm{Cu}), 27 \%(\mathrm{~Pb}), 46 \%(\mathrm{Zn})$, and $38 \%(\mathrm{Fe})$ of the samples in the lagoon. Furthermore, 12\% (Cr), 27\% (Co), 4\% (Cu), 73\% (Pb), 100\% (Se), and $54 \%(\mathrm{Zn})$ of the samples are categorized as "extremely polluted" (Table 4 and Figure 8B). 
Table 4. Potentially toxic element pollution indices.

\begin{tabular}{|c|c|c|c|c|c|c|c|c|c|c|c|c|c|c|c|c|c|c|c|c|c|c|c|c|c|c|c|}
\hline \multirow[t]{2}{*}{$\begin{array}{l}\text { Sample } \\
\text { Stations } \\
\end{array}$} & \multicolumn{9}{|c|}{ Contamination Factor (CF) } & \multicolumn{8}{|c|}{ Enrichment Factor (EF) } & \multicolumn{9}{|c|}{ Ecological Risk Factors (Er) } & \multirow[t]{2}{*}{ RI } \\
\hline & $\mathrm{Cr}$ & Co & $\mathrm{Cu}$ & $\mathrm{Ni}$ & $\mathrm{Pb}$ & Se & $\mathrm{Zn}$ & $\mathrm{Al}$ & $\mathrm{Fe}$ & $\mathrm{Cr}$ & Co & $\mathrm{Cu}$ & $\mathrm{Ni}$ & $\mathrm{Pb}$ & Se & $\mathrm{Zn}$ & $\mathrm{Fe}$ & $\mathrm{Cr}$ & Co & $\mathrm{Cu}$ & $\mathrm{Ni}$ & $\mathrm{Pb}$ & Se & $\mathrm{Zn}$ & Al & $\mathrm{Fe}$ & \\
\hline St 1 & 0.1 & 0.0 & 0.0 & 0.0 & 0.3 & 142.3 & 0.1 & 0.0 & 0.0 & 24.8 & 15.1 & 18.3 & 4.7 & 141.6 & $59,160.3$ & 48.5 & 9.9 & 0.1 & 0.0 & 0.2 & 0.0 & 1.7 & 142.3 & 0.1 & 0.0 & 0.0 & 144.4 \\
\hline St 2 & 0.0 & 0.0 & 0.0 & 0.0 & 0.2 & 166.2 & 0.2 & 0.0 & 0.0 & 6.9 & 5.2 & 9.7 & 4.4 & 47.2 & $43,916.1$ & 57.4 & 10.1 & 0.1 & 0.0 & 0.2 & 0.0 & 0.9 & 166.2 & 0.2 & 0.0 & 0.0 & 167.6 \\
\hline St 4 & 0.1 & 0.3 & 0.0 & 0.1 & 0.4 & 126.0 & 0.3 & 0.0 & 0.2 & 9.1 & 44.3 & 7.4 & 10.6 & 53.5 & $19,102.9$ & 41.9 & 23.9 & 0.1 & 0.3 & 0.2 & 0.1 & 1.8 & 126.0 & 0.3 & 0.0 & 0.2 & 129.0 \\
\hline St 5 & 1.1 & 0.5 & 0.1 & 0.1 & 0.8 & 66.4 & 0.9 & 0.0 & 0.3 & 88.3 & 44.1 & 9.0 & 7.9 & 66.0 & 5473.4 & 75.2 & 26.9 & 2.1 & 0.5 & 0.5 & 0.1 & 4.0 & 66.4 & 0.9 & 0.0 & 0.3 & 74.8 \\
\hline St 6 & 0.7 & 0.5 & 0.2 & 0.2 & 0.7 & 114.4 & 1.2 & 0.0 & 0.2 & 62.5 & 49.0 & 19.4 & 17.9 & 61.4 & $10,261.0$ & 104.4 & 22.1 & 1.4 & 0.5 & 1.1 & 0.2 & 3.4 & 114.4 & 1.2 & 0.0 & 0.2 & 122.4 \\
\hline St 7 & 0.0 & 0.3 & 0.1 & 0.1 & 0.5 & 129.7 & 0.8 & 0.0 & 0.2 & 2.8 & 27.1 & 10.6 & 4.0 & 35.9 & $\begin{array}{l}10,099.7\end{array}$ & 58.5 & 15.8 & 0.1 & 0.3 & 0.7 & 0.1 & 2.3 & 129.7 & 0.8 & 0.0 & 0.2 & 134.2 \\
\hline St 8 & 0.0 & 0.4 & 0.0 & 0.0 & 0.3 & 119.1 & 0.3 & 0.0 & 0.1 & 6.9 & 81.1 & 5.2 & 6.7 & 68.6 & $24,908.0$ & 62.6 & 30.9 & 0.1 & 0.4 & 0.1 & 0.0 & 1.6 & 119.1 & 0.3 & 0.0 & 0.1 & 121.7 \\
\hline St 9 & 0.0 & 0.3 & 0.0 & 0.0 & 0.3 & 142.6 & 0.3 & 0.0 & 0.1 & 8.6 & 86.4 & 6.5 & 8.4 & 70.6 & $37,594.9$ & 76.2 & 32.3 & 0.1 & 0.3 & 0.1 & 0.0 & 1.3 & 142.6 & 0.3 & 0.0 & 0.1 & 144.8 \\
\hline St 11 & 0.1 & 0.8 & 0.1 & 0.1 & 0.6 & 53.0 & 0.7 & 0.0 & 0.4 & 4.3 & 33.5 & 5.8 & 5.2 & 26.0 & 2129.9 & 27.3 & 16.2 & 0.2 & 0.8 & 0.7 & 0.1 & 3.2 & 53.0 & 0.7 & 0.0 & 0.4 & 59.1 \\
\hline St 12 & 0.0 & 0.1 & 0.1 & 0.0 & 0.5 & 160.9 & 0.2 & 0.0 & 0.1 & 9.7 & 37.6 & 23.2 & 2.0 & 132.6 & $42,146.7$ & 50.7 & 22.4 & 0.1 & 0.1 & 0.4 & 0.0 & 2.5 & 160.9 & 0.2 & 0.0 & 0.1 & 164.3 \\
\hline St 13 & 0.0 & 0.2 & 0.0 & 0.0 & 0.5 & 162.1 & 0.3 & 0.0 & 0.1 & 7.9 & 35.5 & 5.3 & 3.4 & 93.3 & $33,111.7$ & 56.6 & 22.1 & 0.1 & 0.2 & 0.1 & 0.0 & 2.3 & 162.1 & 0.3 & 0.0 & 0.1 & 165.2 \\
\hline St 14 & 0.1 & 0.1 & 0.1 & 0.0 & 0.6 & 201.5 & 0.2 & 0.0 & 0.1 & 7.5 & 10.1 & 8.8 & 2.3 & 77.7 & $27,959.9$ & 29.3 & 12.2 & 0.1 & 0.1 & 0.3 & 0.0 & 2.8 & 201.5 & 0.2 & 0.0 & 0.1 & 205.1 \\
\hline St 15 & 0.4 & 0.1 & 0.0 & 0.0 & 0.6 & 189.3 & 0.2 & 0.0 & 0.1 & 64.9 & 17.9 & 7.6 & 3.3 & 93.7 & $32,003.0$ & 32.7 & 14.6 & 0.8 & 0.1 & 0.2 & 0.0 & 2.8 & 189.3 & 0.2 & 0.0 & 0.1 & 193.5 \\
\hline St 16 & 0.1 & 0.1 & 0.1 & 0.0 & 0.3 & 161.7 & 0.2 & 0.0 & 0.1 & 9.0 & 19.5 & 9.1 & 6.1 & 45.8 & $22,894.2$ & 28.0 & 15.7 & 0.1 & 0.1 & 0.3 & 0.0 & 1.6 & 161.7 & 0.2 & 0.0 & 0.1 & 164.1 \\
\hline St 17 & 0.0 & 0.2 & 0.0 & 0.0 & 0.5 & 150.2 & 0.2 & 0.0 & 0.1 & 7.0 & 29.6 & 5.6 & 3.0 & 82.7 & $24,514.2$ & 40.0 & 18.9 & 0.1 & 0.2 & 0.2 & 0.0 & 2.5 & 150.2 & 0.2 & 0.0 & 0.1 & 153.5 \\
\hline St 18 & 0.1 & 0.3 & 0.1 & 0.1 & 0.5 & 135.7 & 0.3 & 0.0 & 0.2 & 5.0 & 26.6 & 7.3 & 5.9 & 41.9 & $12,578.6$ & 27.7 & 15.2 & 0.1 & 0.3 & 0.4 & 0.1 & 2.3 & 135.7 & 0.3 & 0.0 & 0.2 & 139.4 \\
\hline St 19 & 0.0 & 0.3 & 0.1 & 0.0 & 0.4 & 125.0 & 0.3 & 0.0 & 0.2 & 6.1 & 32.5 & 6.7 & 5.8 & 52.3 & $15,980.6$ & 40.5 & 21.2 & 0.1 & 0.3 & 0.3 & 0.0 & 2.0 & 125.0 & 0.3 & 0.0 & 0.2 & 128.2 \\
\hline St 20 & 0.0 & 0.1 & 0.0 & 0.0 & 0.4 & 186.0 & 0.2 & 0.0 & 0.1 & 6.6 & 18.8 & 8.1 & 3.2 & 78.2 & $39,514.4$ & 41.3 & 14.1 & 0.1 & 0.1 & 0.2 & 0.0 & 1.8 & 186.0 & 0.2 & 0.0 & 0.1 & 188.5 \\
\hline St 21 & 0.0 & 0.1 & 0.1 & 0.0 & 0.4 & 120.6 & 0.2 & 0.0 & 0.1 & 5.0 & 15.7 & 6.7 & 4.3 & 43.3 & $14,483.3$ & 28.9 & 17.4 & 0.1 & 0.1 & 0.3 & 0.0 & 1.8 & 120.6 & 0.2 & 0.0 & 0.1 & 123.2 \\
\hline St 22 & 0.1 & 0.6 & 0.2 & 0.1 & 0.7 & 114.9 & 0.5 & 0.0 & 0.2 & 10.1 & 43.4 & 14.4 & 6.0 & 49.5 & 7740.7 & 35.7 & 15.1 & 0.3 & 0.6 & 1.1 & 0.1 & 3.7 & 114.9 & 0.5 & 0.0 & 0.2 & 121.4 \\
\hline St 25 & 0.1 & 0.7 & 0.2 & 0.1 & 0.7 & 74.7 & 1.2 & 0.0 & 0.5 & 5.8 & 33.0 & 7.4 & 5.4 & 30.0 & 3383.9 & 55.2 & 21.1 & 0.3 & 0.7 & 0.8 & 0.1 & 3.3 & 74.7 & 1.2 & 0.0 & 0.5 & 81.6 \\
\hline St 26 & 0.1 & 0.6 & 0.3 & 0.1 & 0.8 & 120.6 & 1.4 & 0.0 & 0.2 & 3.7 & 16.8 & 8.6 & 2.7 & 21.7 & 3185.9 & 37.7 & 4.0 & 0.3 & 0.6 & 1.6 & 0.1 & 4.1 & 120.6 & 1.4 & 0.0 & 0.2 & 128.9 \\
\hline
\end{tabular}



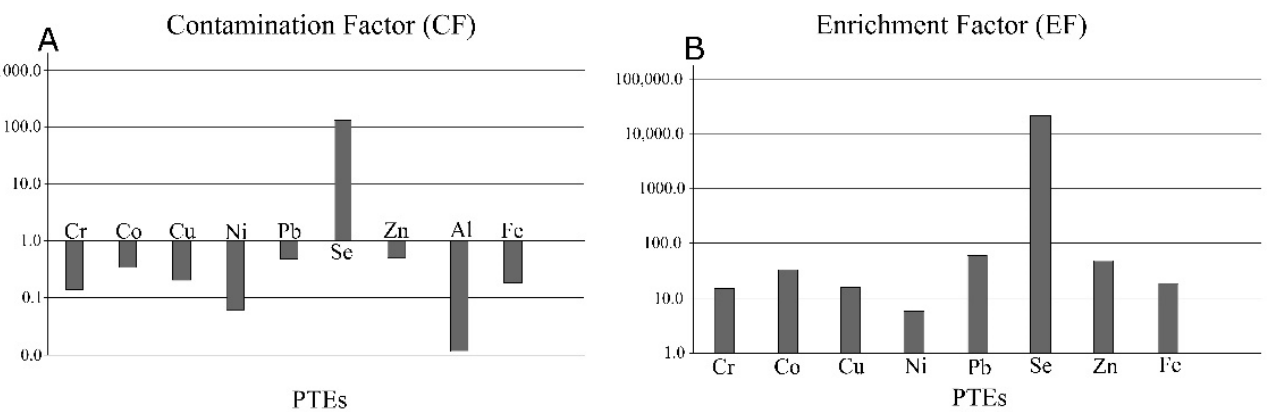

PTEs

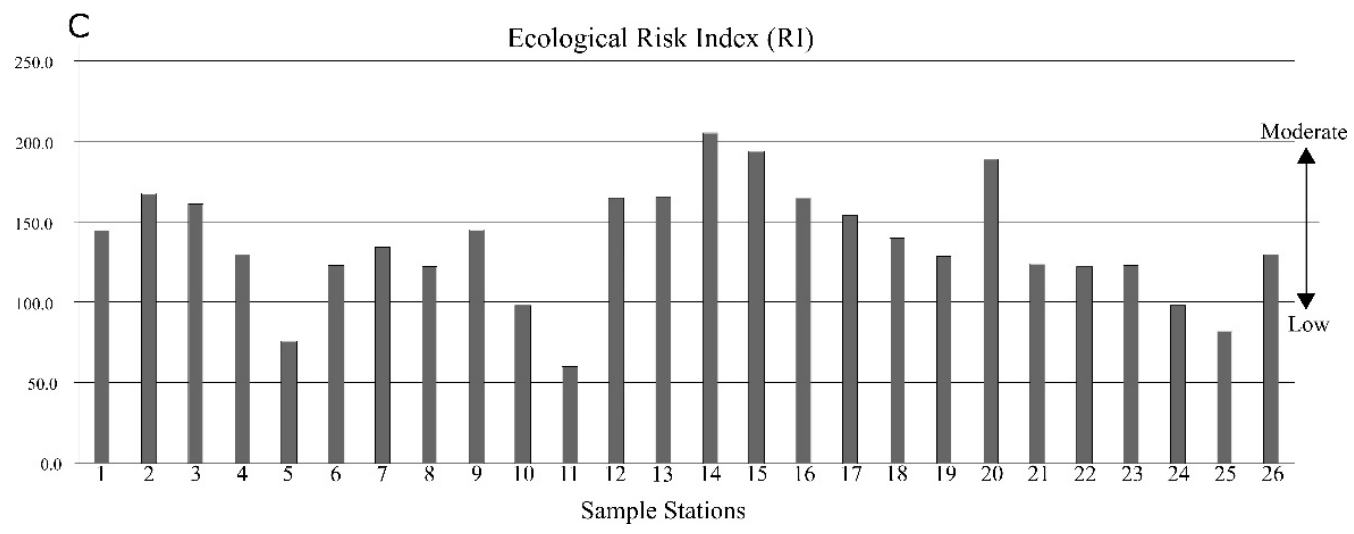

Figure 8. Single element and multi element indices of pollution. (A) Contamination Factor (CF), (B) Enrichment Factor (EF), and (C) Ecological risk index (RI). PTEs: potentially toxic elements.

The RI is an independent ecological assessment tool that considers PTE toxicity in sediments and their Er in the environment with respect to background values (e.g., [29,30]). The Er and RI values are shown in Table 4. Most of the PTEs show low Er values except for Se which is exceptionally high. Moreover, the summative RI index values range between 59 (low) and 205 (moderate) across the sample stations (Table 4 and Figure 8C). Most of the high values of RI are due to the Se concentrations.

\section{Discussion}

Lagos Lagoon is an extremely dynamic ecosystem and has experienced significant human interference for more than 100 years [31]. This includes a growing population entailing large space demands, a rapid depletion of wetlands with increasing urbanization, and the construction of a harbor mole to facilitate navigation through a permanent lagoonal entrance channel. Driven by growth and industrialization, the lagoon receives enormous amounts of largely untreated industrial and other wastes with significant toxic potential. As described previously, most of the pollution in the lagoon is considered to be of anthropogenic origin [6,18,32-34]. The pollution loads recorded within the lagoon represent a cocktail of environmental contaminants, have a significant toxic potential for humans, and wildlife and include heavy metals such as mercury and cadmium, as well as organic compounds polychlorinated biphenyls (PCBs), phenols, and PAHs [34]. To assess the status of pollution and the effect of individual PTEs on the distribution of previously studied benthic foraminifera, we performed an in-depth cross-correlation analysis across Lagos Lagoon.

\subsection{Potentially Toxic Elements in Sediments}

Previous studies have demonstrated that most anthropogenic inputs are concentrated along the western shoreline before fanning out into the lagoon $[19,35,36]$. The east and west spatial distribution of PTEs is related to their affinity to adsorb to clay surfaces present in mud sediments under toxic environmental conditions (F1 fraction; [37]). In this study, we recorded consistently high individual contamination levels along the western lagoon 
shores for $\mathrm{Co}, \mathrm{Al}, \mathrm{Fe}$, and $\mathrm{Zn}$ in the $\mathrm{F} 1$ fraction, for $\mathrm{Ni}$ in the $\mathrm{F} 2$ fraction, for $\mathrm{Cr}$ and $\mathrm{Ni}$ in the $\mathrm{F} 3$ fraction, and for $\mathrm{Co}, \mathrm{Ni}$, and $\mathrm{Fe}$ in the F4 fraction (Figures 5 and 6; Table 4; Appendix ATable A1). However, given the relative acidic conditions of the lagoon (pH: 5.8-6.9), it is probable that the F2/F3 fractions are not significantly sequestered during carbonate mineralization $[1,38]$. This may explain the very low concentration found in the respective exchangeable and acid-soluble fractions (Figure 6). Interestingly, most PTEs are found in the F3 fraction as a response to oxygen levels (Figure 6) related to water column mixing during tidal flushing (0.6-1.2 m; [3]). During iron-oxide precipitation, PTEs will be sequestered and/or adsorb to this reducible fraction as evidenced by Se comprising $95.9 \%$ of the PTEs in the F3 fraction.

The F4 fraction contains relatively high bioavailable PTE concentrations (Figure 6; Appendix A-Table A1) as a response to complexation due to organic pollution (e.g., sewage) and flocculation of organic matter typical of estuarine environments [39]. Among the PTEs analyzed, $\mathrm{Cu}$ has been shown to constitute a proxy for the amount of sewage input (e.g., [40,41]). Since the lagoon receives copious amounts of sewage (e.g., [16,32]), this could explain the high abundance of this PTE in the F4 (oxidizable).

In general, PTEs have shown that $65 \%$ and $35 \%$ of the sampled stations have "low" and "moderate" levels of ecological risk, respectively. This variation is related to the sample stations (ST15-ST20) under a "moderate" level of ecological risk, consisting of very low TOC with sandy sediments and a high number of calcareous foraminifera in the central portion of the lagoon. The sole fractionation of Se with oxide-hydroxides associated with the F3-reducible fraction further indicates that this portion of the lagoon is more oxygenated. On the contrary, the sample stations with "low" ecological risk are located in the western and eastern sectors of the lagoon and consist of high TOC muddy sediments dominated by agglutinated foraminifera. In this case, the negative correlation of Se with TOC and mud suggests that these portions of the lagoon are less oxygenated, maintaining this PTE in other insoluble forms such as its elemental state or as selenide [42].

In addition, highly polluted conditions are indicated by the amount of Selenium which is consistent with reports of other PTEs (e.g., Zn) being released and transported by artificial canals, streams, and rivers from industrial effluents $[35,43,44]$. Unfortunately, the sources of the high pollution status of Se in single and multi-element pollution indices (CF, EF, and RI) are not yet known, and there is no previous literature on the analysis of this PTE in Lagos Lagoon. Moreover, the mobilization of Se in aquatic systems could be a result of anthropogenic activities, such as petroleum transport/oil refining, metal smelting, municipal landfills, and paint production amongst others (e.g., [45-47]), which are prevalent around the lagoon. Other studies have also shown that bioaccumulation along food chains can be another factor responsible for Se mobilization and cycling in aquatic ecosystems [48]. Furthermore, calculations of the Enrichment Factor (EF) show that most of the PTEs analyzed indicate a "moderately" to "extremely" polluted environment. This is compatible with the high PTE values found by Don-Pedro et al. [35].

The total Se distribution map suggests that the source of pollution could come from the northern and southern shores. "High" Se concentrations have only been reported by Overah et al. [49] in urban-derived sediments found in gutters along the Lagos Bar Beach (eastern shore of the Commodore Channel), but neither actual concentrations nor the source of the PTE was provided. The Five Cowrie Creek is a narrow tidal channel connecting the Commodore Channel to the central portion of the lagoon [14]. This bypassing of marine waters into the central part of the lagoon provides a pathway for Se, as demonstrated by a "hotspot" located at the central part of the lagoon (Figure 5; Appendix B-Figure A3). Given that PTEs are found as organo-metallic compounds in the oil, another source of Se most likely could come from the Apapa-Badagry Creek in the Lagos Harbor which is known to have high concentrations of hydrocarbons (PAHs) [5]. The levels and detrimental effects of Se in Lagos Lagoon have not been studied so far, which explains how this PTE's enrichment could go unnoticed over such a long period of time. 


\subsection{Correlation between PTEs and Benthic Foraminiferal Assemblages}

Several workers have reported the influence of PTEs on the distribution and diversity of benthic foraminifera especially in estuarine-lagoon environments (e.g., [2,38,50-52]). However, the concept of using total and bioavailable PTE concentrations does not directly apply when used as an assessment of the ecological response of benthic foraminifera to pollutants $[1,37,53]$. The degree of uncertainty when using total concentrations does not allow for the proper assessment of PTE impacts. For example, A. salsum, Trochammina sp. 1 , and the percentage values of agglutinated taxa have significant positive correlations with several PTEs in the -F3 bioavailable and total concentrations, while hyaline-perforate mostly had negative correlations (Table 3). However, the PTEs in this fraction are not readily bioavailable to the foraminifera, given that they are sequestered within the crystalline structures of oxides after precipitation. Based on the generalized feeding habits (e.g., detritivory, omnivory) of foraminifera, it is suspected that PTEs found in the F1 and F4 fractions are the most bioavailable and should be only considered when assessing the impacts of these contaminants.

In Lagos Lagoon, the foraminiferal species richness was shown to be comparatively low (42 taxa; [13]), a feature that is common in estuarine and lagoonal habitats [3,54-56]. Species richness, however, did not show any significant correlation with the PTEs in any fraction, but non-significant negative correlations were observed for $\mathrm{Co}_{\mathrm{F} 2, \mathrm{~F} 3, \mathrm{~F} 4}, \mathrm{Ni}_{\mathrm{F} 2, \mathrm{~F} 4}$; $\mathrm{Pb}_{\text {total }}, \mathrm{Se}_{\mathrm{F} 2}, \mathrm{Al}_{\mathrm{F} 3}, \mathrm{Fe}_{\mathrm{F} 2}, \mathrm{Zn}_{\mathrm{F} 3}$, and TOC. A statistically significant positive correlation, however, was recorded between species richness and percent abundances of foraminifera with a porcelaneous test wall (Table 3). As pointed out by Fajemila et al. [13,57], foraminiferal species richness and abundances of porcelaneous taxa are primarily driven by salinity, suggesting that the individual PTEs or fractions thereof have secondary importance for species with a porcelaneous test wall.

Agglutinated taxa are interchangeably abundant with calcareous taxa along different corridors of the lagoon with respect to sediment characteristics and salinity values governed by the interplay between marine and fresh waters [13]. For example, A. salsum, which is widely recognized as a stress-tolerant species (e.g., [52,58-60]), coupled with Trochammina sp. 1 occupies most of the easterly and westerly sites in the lagoon (Figure 2). Ammotium salsum and Trochammina sp. 1 were found to have significant positive correlations with $\mathrm{Cr}_{\mathrm{F} 4}-\mathrm{Co}_{\mathrm{F} 2-\mathrm{F} 3-\mathrm{F} 4 \text {-total }}-\mathrm{Cu}_{\mathrm{F} 4 \text {-total }}-\mathrm{Ni}_{\mathrm{F} 3 \text {-F4-total }}-\mathrm{Al}_{\mathrm{F} 4 \text {-total }}-\mathrm{Fe}_{\mathrm{F} 3-\mathrm{F} 4 \text {-total }}-\mathrm{Zn}_{\mathrm{F} 3 \text {-F4-total }}$ and correlate negatively with $\mathrm{Pb}_{\mathrm{F}_{4}}-\mathrm{Se}_{\mathrm{F} 3}-\mathrm{Se}_{\text {total }}$. Oxidizable fraction (F4) is directly related to organic matter, and potentially bioavailable along trophic transfer lines $[1,37,52]$. The overall significant positive correlation of these PTEs suggests that they behave as micronutrients and not as stressors when complexed with organic matter in the GoG. A positive correlation between the \% abundances of agglutinated taxa and TOC (Table 3) provides additional support for this hypothesis. In addition, positive correlation records between percent abundances of agglutinated foraminifera, D, and FN (Table 3) show that besides TOC, salinity plays a major role. A similar finding was reported from west African lagoons by Debenay [61], who identified A. salsum as a stress-tolerant species following salinity gradients. Although it is difficult to disentangle which vector gradient (pollution vs. salinity) is responsible for their dominance and distribution patterns, both $A$. salsum and Trochammina sp. 1 are considered bioindicators of environmental stress in Lagos lagoon given their affinity to PTEs in the organic-bound F4 fraction.

It is important to notice that the percent abundances of agglutinated foraminifera correlate positively with several PTEs in the F3-total fractions. Because these fractions are not readily bioavailable, they may represent false positives. For example, the positive correlation between mud and TOC strongly suggests that organic-rich muddy sediments are dominant in the lagoon. Since organic matter plays an integral role in the level of oxygenation, it comes as no surprise that the percentage of agglutinate foraminifera correlates positively with PTEs in the iron-oxide (F3) fraction.

The significant positive correlation of both A. salsum and Trochammina sp. 1 with TOC supports the affinity of certain PTEs to organic matter. As shown by Fajemila et al. [13], the 
abundance is highest where there are low salinity readings which coincides with higher amounts of TOC with PTEs complexed in the F4 fraction. The single PTE that negatively correlates with $A$. salsum and Trochammina sp. 1 is $\mathrm{Pb}_{\mathrm{F} 4}$, suggesting that it is the only PTE with a detrimental effect on the distribution of the two species.

Among all hyaline-perforate benthic foraminifera present in Lagos Lagoon, members of the genus Ammonia were found to constitute the most abundant. Several species of the genus Ammonia are well-known to be a stress-tolerant (e.g., [62-64]). Ammonia, however, shows no correlation with mud and TOC. Its highest abundances were found to be at sites around the center of the lagoon where TOC values are $<4 \%$ (Figure 2). This particular Ammonia distribution could be linked to variable $\mathrm{pH}$ conditions, and culture experiments have documented that drastic decalcification occurs when $\mathrm{pH}$ approaches 7 [65]. Similarly, Pettit et al. [66] found very few specimens of Ammonia in both the living and dead assemblages at $\mathrm{pH}$ levels between 7.55-7.88 in the Gulf of California. Acidic lagoon conditions of Lagos Lagoon ( $\mathrm{pH}$ 5.8-6.9) may therefore limit the abundance of calcareous taxa, a feature that is also supported by the lack of correlation between $\mathrm{CaCO}_{3}$ and $A$. aoteana. This hypothesis is consistent with the observations of Dias et al. [67] who studied the long-term biological response of foraminifera to acidification and reported foraminiferal assemblages dominated by agglutinated taxa at $\mathrm{pH}<7.6$. In addition, the negative correlation between percent abundances of hyaline-perforate taxa with both TOC and FN (Table 3) suggests that the environmental conditions at high TOC values favor agglutinated over hyaline-perforate taxa.

Although $A$. aoetana is the dominant hyaline-perforate taxon with practically no correlation with PTEs, the percentage of the hyaline group shows numerous significant correlations with non-bioavailable $\mathrm{Co}_{\mathrm{F} 2-\mathrm{F} 3 \text { total }}-\mathrm{Cu}_{\mathrm{F} 2-\mathrm{F} 3 \text {-total }}-\mathrm{Pb}_{\mathrm{F} 3 \text {-total }}-\mathrm{Se}_{\mathrm{Fe} \text {-total }}-\mathrm{Al}_{\text {total }}-\mathrm{Fe}_{\mathrm{F} 3 \text {-total }}-\mathrm{Zn}_{\mathrm{F} 3 \text {-total }}$. However, this $\mathrm{PTE}_{\mathrm{F} 3}$ fraction is not bioavailable and is considered a false positive as it has no direct effect on this group. Interestingly, the percentage of hyaline-perforate taxa correlates positively with bioavailable $\mathrm{Pb}_{\mathrm{F} 4}$, suggesting that the latter behaves like a micronutrient. However, TOC shows a strong negative correlation with both $\mathrm{Pb}_{\mathrm{F} 4}$ and the percentage of hyaline-perforate taxa (Table 3).

As pointed by Martinez-Colón et al. [1], PTEs in the exchangeable fraction (F1) could be bioavailable to the foraminifera. A positive correlation was found for $\mathrm{Al}_{\mathrm{F} 1}$ with mud, indicating that the sediment provenance is mostly terrestrial. $\mathrm{Co}_{\mathrm{F} 1}$ also correlates positively with Trochammina sp. 1 and negatively with A. aoteana, suggesting that it functions both as a micronutrient and a stressor, respectively. No other PTE in the F1 exchangeable fraction correlates significantly with A. salsum, Trochammina sp. 1, or A. aoteana.

The low foraminiferal ecological risk index values recorded are characteristic for stressed environments (e.g., [68,69]). For example, H(S) only correlates negatively with Co$\mathrm{Ni}-\mathrm{Pb}-\mathrm{Fe}$ in the $\mathrm{F} 4$ fraction and with $\mathrm{TOC}$ and $\% \mathrm{CaCO}_{3}$. This suggests that a multitude of variables, including low dissolved oxygen, variable water acidification (linked to salinity), and aforementioned bioavailable PTEs are impacting the composition and distribution of assemblages. Similarly, the statistical relationship between foraminiferal dominance (D) values with TOC, $\mathrm{CaCO}_{3}$, and several PTEs suggests the same effects on the dominance and distribution of $A$. salsum.

Previously recorded data showed that the foraminiferal number $(\mathrm{FN})$ increases westeast across the lagoon with an accompanying decrease in species richness [13]. FN correlates positively with $\mathrm{Co}-\mathrm{Ni}-\mathrm{Al}-\mathrm{Fe}-\mathrm{Zn}$ and negatively with $\mathrm{Pb}$ in the $\mathrm{F} 4$ fraction. This suggests that besides salinity, the composition and texture of sediments play a factor in the foraminiferal distribution. In addition, the sediments showing a significant positive correlation with mud and TOC, suggest that several PTEs or fractions thereof play an auxiliary role.

Previous studies reported that under conditions of heavy metal pollution foraminiferal population density tends to decline but that a suite of environmental factors can make parsing the effect of contaminants from other variables difficult [70-75]. Recent studies by Smith and Goldstein [73] showed that exposure to elevated concentrations of Ni and Zn resulted in limited abundances under varying salinity and temperature conditions. The effects on species richness and test deformities, however, remained puzzling and 
inconsistent. No significant positive correlation with none of the PTEs was found for neither species richness nor for the most abundant hyaline-perforate species (A. aoteana) in Lagos Lagoon. Previously recorded data from Lagos Lagoon showed that the FN in total assemblages increased west-east across the lagoon with an accompanying decrease in species richness and salinity [13]. Total abundances were recorded to correlate positively with $\mathrm{Co}-\mathrm{Ni}-\mathrm{Al}-\mathrm{Fe}-\mathrm{Zn}$ and negatively with $\mathrm{Pb}$ in the F4 fraction. Therefore, the spatial distribution of foraminiferal diversity is best explained by their negative correlation with $\mathrm{Co}_{\mathrm{F} 4}-\mathrm{Ni}_{\mathrm{F} 4}-\mathrm{Fe}_{\mathrm{F} 4}$, as it also follows salinity gradients. On the contrary, positive correlations exist between $\mathrm{Co}_{\mathrm{F} 4}-\mathrm{Cu}_{\mathrm{F} 4}-\mathrm{Ni}_{\mathrm{F} 4}-\mathrm{Al}_{\mathrm{F} 4}-\mathrm{Fe}_{\mathrm{F} 4}-\mathrm{Zn}_{\mathrm{F} 4}, \mathrm{FN}$, and TOC, suggesting that these PTEs behave as micronutrients.

Except for $\mathrm{Se}_{\mathrm{F} 4}$ and $\mathrm{Pb}_{\mathrm{F} 4}$, no significant and consistent negative correlation between the abundance, species richness, and spatial distribution of benthic foraminifera and PTEs was found in Lagos Lagoon. We acknowledge that the PTEs analyzed in this study represent only a fraction of the pollution cocktail accumulating within Lagos Lagoon. Especially in the industrialized western part of the lagoon, other toxic substances, including PAHs, PCBs, and high concentrations of organic compounds, were reported to have detrimental and lethal effects on marine life [1,2,76,77].

\section{Conclusions}

Foraminiferal assemblages collected across the highly polluted Lagos Lagoon display a distinct separation of agglutinated and hyaline-perforate/porcelaneous taxa. The spatial separation is largely oriented along the salinity contour lines. Superimposed on the salinity-driven distributional differences are a multitude of stressors related to increasing anthropogenic influences. Our in-depth cross-correlation analysis on the spatial distribution foraminifera and a selection of Potentially Toxic Elements (PTEs) yields the following major conclusions:

1. The results of our study do not show a significant negative correlation between benthic foraminiferal species and PTEs except for $\mathrm{Pb}_{\mathrm{F} 4}$ and $\mathrm{Se}_{\mathrm{F} 4}$.

2. The spatial distribution of foraminiferal species richness and diversity negatively correlates with $\mathrm{Co}_{\mathrm{F} 4}-\mathrm{Ni}_{\mathrm{F} 4}-\mathrm{Fe}_{\mathrm{F} 4}$, a feature that tracks the salinity gradients. On the contrary, the positive correlation of $\mathrm{Co}_{\mathrm{F} 4}-\mathrm{Cu}_{\mathrm{F} 4}-\mathrm{Ni}_{\mathrm{F} 4}-\mathrm{Al}_{\mathrm{F} 4}-\mathrm{Fe}_{\mathrm{F} 4}-\mathrm{Zn}_{\mathrm{F} 4}$ with the foraminiferal number distribution suggests that these PTEs behave as micronutrients since it also correlates favorably with TOC.

3. This study provides new information on the bioavailability of PTEs, especially of Se in Lagos Lagoon. The relatively high concentrations of Se suggest that it has been accumulated unnoticed in the lagoon over the years. Lagos Lagoon will continue to act as a sink for Se and other PTEs, therefore, their potential impact on the lagoon's ecosystem must be monitored and assessed for proper management and control to minimize further impacts of all these pollutants on coastal activities.

4. Shannon diversity values $\mathrm{H}(\mathrm{S})$ show significant negative correlations with various bioavailable PTEs in the F4 fraction (Co-Ni-Fe).

5. An interesting finding is Se being the only PTE with the highest total concentration (32-120 mg/kg) within the central portion of the lagoon. The Ecological Risk Index and Enrichment Factor also suggest that this part of the lagoon is experiencing moderate to severely polluted environmental conditions. It is uncertain what the extent of its effects on the foraminiferal assemblages is, since the abundance of A. salsum and Trochammina sp. 1, and the FN are the only parameters showing significant negative correlations with the non-bioavailable fractions of Se.

6. Our study serves as a baseline for future studies investigating the environmental impact of pollution on benthic foraminifera, species richness, and within the Lagos Lagoon environment. Because the PTEs analyzed in this study represent only a portion of the pollution cocktail accumulating within Lagos Lagoon, future analysis of PAHs, PCBs, and OCs would provide a more comprehensive view on the status of pollution and their effects on foraminiferal bioindicators. Consistent with previous work, our 
results identify the problems associated with using total concentrations of selected PTEs alone as tools for biomonitoring, but support the usefulness of foraminiferal abundance and species richness as tools for environmental analysis.

Author Contributions: Conceptualization, O.T.F. and M.R.L.; methodology, O.T.F., M.M.-C. and M.R.L.; investigation, O.T.F., M.M.-C. and I.S.C.; resources, M.M.-C. and M.R.L.; formal analysis, O.T.F., M.M.-C., N.S., I.S.C. and T.O.K.; writing-original draft preparation, O.T.F., M.M.-C., N.S., I.S.C., T.O.K. and M.R.L.; writing-review and editing, O.T.F., M.M.-C., N.S. and M.R.L.; visualization, O.T.F., M.M.-C. and M.R.L.; supervision, M.R.L.; funding acquisition, O.T.F., M.M.-C. and M.R.L. All authors have read and agreed to the published version of the manuscript.

Funding: This work was supported by grants from the Tertiary Education Tax Fund Nigeria (www. tetfund.gov.ng, accessed on 20 May 2019) to O.T.F. (TETFund/16b/0014), the German Science Foundation (DFG; www.dfg.de, accessed on 23 November 2021) to MRL (LA 884/10-1, LA 884/5-1), the National Science Foundation Geography and Spatial Sciences Program to M.M.-C. (grant number 1853794), and the Early Career Research Fellowship from the Gulf Research Program of the National Academies of Sciences, Engineering, and Medicine to M.M.-C. (grant number 2000009944). The content of this publication is the solely the responsibility of the authors and funders were not involved in the study design, data collection and analysis, interpretations, decision to publish, or preparation of the manuscript.

Data Availability Statement: The datasets generated and/or analyzed during the current study are included in this article.

Acknowledgments: The authors gratefully acknowledge support from the Nigerian Institute of Oceanography and Marine Research (NIOMR) and Sina Adegbie for processing samples.

Conflicts of Interest: The authors declare no conflict of interests.

\section{Appendix A}

PTE concentrations for each fraction (F1-F4).

Table A1. PTE concentrations for each fraction. Concentrations are in $\mathrm{mg} / \mathrm{kg}$ and in percent $\left(^{*}\right)$. (BDL = Below Detection Limit).

\begin{tabular}{|c|c|c|c|c|c|c|c|c|c|c|c|c|}
\hline \multirow{2}{*}{ Sample ID } & \multicolumn{12}{|c|}{ Fraction \#1 (F1: Exchangeable) } \\
\hline & $\mathrm{Cr}$ & Co & $\mathrm{Cu}$ & $\mathrm{Ni}$ & $\mathrm{Cd}$ & $\mathbf{P b}$ & $\mathbf{K}^{*}$ & Se & As & $\mathrm{Al}$ * & $\mathrm{Fe}^{*}$ & Zn \\
\hline 1 & 0.75 & 0.39 & 0.87 & BDL & 2.25 & 1.11 & 0.01 & 0.42 & 0.15 & $1.11 \times 10^{-4}$ & $2.76 \times 10^{-4}$ & 0.57 \\
\hline 2 & 0.18 & BDL & 0.39 & BDL & 0.18 & 0.78 & 0.02 & 0.39 & 0.18 & $1.35 \times 10^{-3}$ & $2.34 \times 10^{-4}$ & 0.24 \\
\hline 3 & BDL & 0.33 & 0.30 & BDL & 0.06 & 0.60 & 0.04 & 0.24 & BDL & $9.3 \times 10^{-5}$ & $2.01 \times 10^{-4}$ & 0.27 \\
\hline 4 & BDL & 0.00 & 0.33 & BDL & 0.00 & 0.75 & 0.09 & 0.48 & BDL & $2.4 \times 10^{-3}$ & $5.49 \times 10^{-4}$ & 0.15 \\
\hline 5 & 0.03 & 0.18 & 0.24 & BDL & 0.12 & BDL & 0.14 & 0.00 & 0.09 & $1.65 \times 10^{-3}$ & $3.16 \times 10^{-3}$ & 0.60 \\
\hline 6 & 0.06 & 0.24 & 0.33 & BDL & 0.42 & BDL & 0.13 & BDL & BDL & $3.88 \times 10^{-3}$ & $7.55 \times 10^{-3}$ & 0.87 \\
\hline 7 & 0.00 & 0.09 & 0.18 & BDL & 0.00 & BDL & 0.06 & 0.15 & $\mathrm{BDL}$ & $2.13 \times 10^{-3}$ & $4.24 \times 10^{-3}$ & 0.21 \\
\hline 8 & BDL & BDL & 0.09 & BDL & BDL & BDL & 0.01 & 0.18 & BDL & $2.55 \times 10^{-4}$ & $7.92 \times 10^{-4}$ & 0.06 \\
\hline 9 & BDL & BDL & 0.09 & BDL & BDL & BDL & 0.01 & 0.03 & 0.09 & $9.3 \times 10^{-5}$ & $3.42 \times 10^{-4}$ & 0.06 \\
\hline 10 & BDL & 0.27 & 0.09 & BDL & 0.03 & BDL & 0.15 & 0.42 & BDL & $2.94 \times 10^{-4}$ & $1.15 \times 10^{-3}$ & 0.24 \\
\hline 11 & 0.00 & 0.15 & 0.12 & BDL & 0.03 & BDL & 0.15 & 0.09 & BDL & $1.6 \times 10^{-3}$ & $3.3 \times 10^{-3}$ & 0.21 \\
\hline 12 & BDL & 0.00 & 3.00 & BDL & BDL & BDL & 0.01 & 0.12 & $\mathrm{BDL}$ & $6.3 \times 10^{-5}$ & $1.44 \times 10^{-4}$ & 0.12 \\
\hline 13 & BDL & 0.00 & 0.12 & BDL & BDL & BDL & 0.01 & 0.15 & BDL & $9.3 \times 10^{-5}$ & $4.47 \times 10^{-4}$ & 0.45 \\
\hline 14 & BDL & 0.03 & 0.09 & BDL & BDL & BDL & 0.06 & 0.30 & BDL & $5.1 \times 10^{-4}$ & $8.22 \times 10^{-4}$ & 0.18 \\
\hline 15 & BDL & 0.06 & 0.09 & BDL & BDL & BDL & 0.04 & 0.24 & BDL & $9.9 \times 10^{-4}$ & $1.4 \times 10^{-3}$ & 0.27 \\
\hline 16 & BDL & 0.06 & 0.09 & BDL & BDL & BDL & 0.05 & 0.12 & 0.09 & $1.03 \times 10^{-3}$ & $1.69 \times 10^{-3}$ & 0.18 \\
\hline 17 & BDL & 0.03 & 0.30 & BDL & BDL & BDL & 0.02 & 0.09 & BDL & $3.54 \times 10^{-4}$ & $8.76 \times 10^{-4}$ & 0.12 \\
\hline 18 & BDL & 0.06 & 0.06 & BDL & 0.00 & BDL & 0.09 & 0.15 & BDL & $2.88 \times 10^{-4}$ & $6.15 \times 10^{-4}$ & 0.18 \\
\hline 19 & BDL & 0.06 & 0.09 & BDL & BDL & BDL & 0.05 & 0.21 & BDL & $2.46 \times 10^{-4}$ & $6.3 \times 10^{-4}$ & 0.12 \\
\hline 20 & BDL & 0.03 & 0.09 & BDL & BDL & BDL & 0.03 & 0.24 & BDL & $2.13 \times 10^{-4}$ & $4.41 \times 10^{-4}$ & 0.12 \\
\hline 21 & BDL & 0.00 & 0.06 & BDL & BDL & BDL & 0.05 & 0.33 & BDL & $4.65 \times 10^{-4}$ & $9.42 \times 10^{-4}$ & 0.21 \\
\hline 22 & BDL & 0.06 & 0.09 & BDL & 0.00 & BDL & 0.07 & 0.57 & BDL & $1.53 \times 10^{-4}$ & $4.17 \times 10^{-4}$ & 0.12 \\
\hline 23 & BDL & 0.18 & 0.06 & BDL & 0.06 & BDL & 0.18 & 0.24 & BDL & $3.54 \times 10^{-4}$ & $7.14 \times 10^{-4}$ & 0.42 \\
\hline 24 & BDL & 0.15 & 0.06 & BDL & 0.03 & BDL & 0.14 & 0.12 & BDL & $4.77 \times 10^{-4}$ & $1.46 \times 10^{-3}$ & 0.27 \\
\hline 25 & 0.45 & 0.33 & 0.33 & BDL & 0.27 & BDL & 0.14 & 0.48 & BDL & $6.9 \times 10^{-4}$ & $4.17 \times 10^{-4}$ & 0.30 \\
\hline 26 & BDL & 0.18 & 0.18 & BDL & 0.39 & BDL & 0.11 & 0.36 & BDL & $1.5 \times 10^{-4}$ & $3.6 \times 10^{-4}$ & 0.57 \\
\hline
\end{tabular}


Table A1. Cont.

\begin{tabular}{|c|c|c|c|c|c|c|c|c|c|c|c|c|c|}
\hline \multirow{2}{*}{ Sample ID } & \multicolumn{13}{|c|}{ Fraction \#2 (F2: Acid-soluble) } \\
\hline & $\mathrm{Cr}$ & Co & $\mathrm{Cu}$ & $\mathbf{N i}$ & $\mathrm{Cd}$ & $\mathrm{Pb}$ & $\mathbf{K}^{*}$ & Se & As & \multicolumn{2}{|c|}{$\mathrm{Al}$ * } & $\mathbf{F e} *$ & $\mathrm{Zn}$ \\
\hline 1 & 0.12 & 0.00 & 0.15 & 0.03 & 0.03 & 0.39 & 0.01 & 1.350 & BDL & \multicolumn{2}{|c|}{$4.77 \times 10^{-4}$} & $6.3 \times 10^{-4}$ & 0.60 \\
\hline 2 & 0.06 & 0.03 & 0.09 & 0.03 & 0.03 & 0.36 & 0.02 & 1.56 & $\mathrm{BDL}$ & \multicolumn{2}{|c|}{$4.02 \times 10^{-4}$} & $4.71 \times 10^{-4}$ & 6.00 \\
\hline 3 & 0.06 & 0.21 & 0.00 & 0.21 & 0.00 & 0.36 & 0.03 & 1.74 & BDL & \multicolumn{2}{|c|}{$9.9 \times 10^{-5}$} & $2.85 \times 10^{-4}$ & 1.20 \\
\hline 4 & 0.06 & 0.18 & BDL & 0.12 & 0.03 & 0.30 & 0.05 & 1.59 & BDL & \multicolumn{2}{|c|}{$5.13 \times 10^{-4}$} & $1.08 \times 10^{-3}$ & 0.81 \\
\hline 5 & 0.09 & 0.05 & 0.12 & 0.06 & 0.03 & 0.66 & 0.10 & 1.71 & BDL & \multicolumn{2}{|c|}{$5.97 \times 10^{-4}$} & $2.1 \times 10^{-3}$ & 2.85 \\
\hline 6 & 0.06 & 0.66 & 0.12 & 0.30 & 0.18 & 0.96 & 0.09 & 1.68 & BDL & \multicolumn{2}{|c|}{$3.27 \times 10^{-4}$} & $1.15 \times 10^{-3}$ & 6.57 \\
\hline 7 & 0.06 & 0.51 & 0.03 & 0.06 & 0.06 & 0.66 & 0.04 & 1.74 & BDL & \multicolumn{2}{|c|}{$4.62 \times 10^{-4}$} & $1.58 \times 10^{-3}$ & 21.00 \\
\hline 8 & 0.06 & 0.09 & 0.09 & 0.06 & 0.00 & 0.27 & 0.02 & 1.89 & BDL & \multicolumn{2}{|c|}{$7.53 \times 10^{-4}$} & $1.13 \times 10^{-3}$ & 0.66 \\
\hline 9 & 0.06 & 0.03 & 0.03 & 0.00 & 0.03 & 0.42 & 0.02 & 2.07 & BDL & \multicolumn{2}{|c|}{$2.76 \times 10^{-4}$} & $6 \times 10^{-4}$ & 0.51 \\
\hline 10 & 0.09 & 1.17 & 0.12 & 0.21 & 0.03 & 0.60 & 0.10 & 1.77 & BDL & \multicolumn{2}{|c|}{$6.78 \times 10^{-4}$} & $5.45 \times 10^{-3}$ & 1.38 \\
\hline 11 & 0.15 & 1.47 & 0.15 & 0.06 & BDL & 2.13 & 0.09 & 1.71 & BDL & \multicolumn{2}{|c|}{$5.76 \times 10^{-4}$} & $4.69 \times 10^{-3}$ & 1.41 \\
\hline 12 & 0.09 & 0.15 & 0.21 & BDL & BDL & 1.77 & 0.01 & 1.80 & BDL & 2.43 & $10^{-4}$ & $3.2 \times 10^{-3}$ & 0.57 \\
\hline 13 & 0.06 & 0.03 & 0.15 & BDL & BDL & 0.84 & 0.02 & 1.89 & BDL & 2.46 & $10^{-4}$ & $7.32 \times 10^{-4}$ & 0.48 \\
\hline 14 & 0.15 & 0.24 & 0.12 & BDL & BDL & 2.64 & 0.03 & 19.80 & $\mathrm{BDL}$ & 4.53 & $10^{-4}$ & $1.27 \times 10^{-3}$ & 0.87 \\
\hline 15 & 0.15 & 0.18 & 0.09 & BDL & BDL & 3.18 & 0.02 & 1.98 & BDL & 3.48 & $10^{-4}$ & $5.76 \times 10^{-4}$ & 0.84 \\
\hline 16 & 0.06 & 0.18 & 0.03 & 0.15 & 0.03 & 0.42 & 0.03 & 2.07 & BDL & & )$^{-4}$ & $1.08 \times 10^{-3}$ & 0.99 \\
\hline 17 & 0.09 & 0.27 & 0.09 & 0.03 & BDL & 1.20 & 0.02 & 0.90 & BDL & 4.35 & $10^{-4}$ & $7.42 \times 10^{-3}$ & 1.23 \\
\hline 18 & 0.06 & 0.21 & 0.03 & 0.21 & 0.00 & 0.60 & 0.04 & 1.77 & BDL & 4.35 & $10^{-4}$ & $8.28 \times 10^{-4}$ & 0.78 \\
\hline 19 & 0.06 & 0.30 & 0.12 & 0.18 & 0.03 & 0.30 & 0.03 & 1.86 & BDL & 3.66 & $10^{-4}$ & $2.07 \times 10^{-3}$ & 1.05 \\
\hline 20 & 0.06 & 0.15 & 0.03 & 0.09 & 0.00 & 0.30 & 0.02 & 1.86 & BDL & 3.45 & $10^{-4}$ & $8.7 \times 10^{-4}$ & 1.17 \\
\hline 21 & 0.06 & 0.18 & 0.06 & 0.18 & 0.03 & 0.30 & 0.03 & 1.83 & BDL & 5.19 & $10^{-4}$ & $2.29 \times 10^{-3}$ & 1.11 \\
\hline 22 & 0.06 & 0.51 & 0.06 & 0.06 & 0.03 & 0.48 & 0.05 & 2.04 & BDL & 1.83 & $10^{-4}$ & $1.22 \times 10^{-3}$ & 2.28 \\
\hline 23 & 0.09 & 0.36 & 0.12 & 0.09 & 0.03 & 0.45 & 0.08 & 1.89 & BDL & 4.2 & $0^{-4}$ & $1.19 \times 10^{-3}$ & 1.71 \\
\hline 24 & 0.21 & 1.02 & 0.24 & 0.33 & 0.18 & 0.45 & 0.12 & 1.56 & BDL & 6.81 & $10^{-4}$ & $5.21 \times 10^{-3}$ & 1.68 \\
\hline 25 & 0.09 & 0.45 & 0.12 & 0.15 & 0.12 & 0.30 & 0.11 & 2.04 & BDL & 2.7 & $0^{-4}$ & $7.17 \times 10^{-4}$ & 2.25 \\
\hline 26 & 0.12 & 0.69 & 0.15 & 0.12 & 0.21 & 0.84 & 0.12 & 2.100 & BDL & 3.87 & $10^{-4}$ & $1.15 \times 10^{-3}$ & 7.35 \\
\hline ComploID & & & & & & Fra & n \#3 (1 & Reduc & & & & & \\
\hline sample ID & $\mathrm{Cr}$ & Co & $\mathrm{Cu}$ & $\mathrm{Ni}$ & $\mathrm{Cd}$ & $\mathrm{Pb}$ & & & Se & As & $\mathrm{Al}$ * & $\mathrm{Fe}^{*}$ & $\mathrm{Zn}$ \\
\hline 1 & 3.6 & 0.3 & 0.6 & 0.6 & 0.3 & 4.5 & 2.01 & $10^{-3}$ & 83.4 & BDL & 0.02 & 0.10 & 9.9 \\
\hline 2 & 1.5 & 0.3 & 0.6 & 0.9 & 0.3 & 1.8 & 2.52 & $10^{-3}$ & 92.1 & BDL & 0.02 & 0.17 & 11.4 \\
\hline 3 & 1.5 & 0.6 & 0.3 & 1.5 & 0.3 & 1.8 & 2.43 & $10^{-3}$ & 93.3 & BDL & 0.01 & 0.22 & 11.4 \\
\hline 4 & 3.9 & 3.9 & 0.0 & 3.3 & BDL & 5.1 & & & 73.5 & BDL & 0.01 & 0.63 & 22.2 \\
\hline 5 & 93.0 & 8.4 & 0.6 & 5.1 & BDL & 15.3 & & & 38.1 & BDL & 0.02 & 1.15 & 70.5 \\
\hline 6 & 60.0 & 8.1 & 0.3 & 11.4 & 0.3 & 12.6 & & & 66.9 & BDL & 0.03 & 0.79 & 89.1 \\
\hline 7 & 2.7 & 4.5 & 0.0 & 2.4 & BDL & 8.4 & & & 75.9 & BDL & 0.02 & 0.56 & 38.1 \\
\hline 8 & 2.4 & 6.6 & 0.6 & 1.8 & BDL & 5.7 & 1.53 & $10^{-3}$ & 66.9 & BDL & 0.02 & 0.68 & 25.8 \\
\hline 9 & 2.1 & 5.4 & 0.6 & 1.8 & BDL & 4.2 & 1.47 & $10^{-3}$ & 81.3 & BDL & 0.01 & 0.56 & 24.6 \\
\hline 10 & 5.7 & 10.2 & 0.6 & 5.7 & BDL & 8.4 & & & 44.1 & BDL & 0.02 & 1.24 & 44.7 \\
\hline 11 & 6.3 & 10.2 & 0.6 & 5.7 & BDL & 10.8 & & & 30.0 & BDL & 0.02 & 1.25 & 45.3 \\
\hline 12 & 2.7 & 2.4 & 0.6 & 0.3 & BDL & 7.8 & 7.80 & $10^{-4}$ & 92.1 & BDL & 0.02 & 0.40 & 17.1 \\
\hline 13 & 2.7 & 3.0 & 0.6 & 0.9 & BDL & 7.5 & 9.00 & $10^{-4}$ & 92.7 & BDL & 0.03 & 0.50 & 24.3 \\
\hline 14 & 2.7 & 0.9 & 0.6 & 0.6 & 0.0 & 7.8 & 3.15 & $10^{-3}$ & 100.8 & BDL & 0.03 & 0.32 & 18.3 \\
\hline 15 & 33.0 & 1.5 & 0.6 & 0.9 & 0.0 & 7.2 & 2.25 & $10^{-3}$ & 111.3 & BDL & 0.02 & 0.35 & 16.5 \\
\hline 16 & 3.3 & 1.8 & 0.3 & 2.1 & 0.0 & 5.4 & 2.73 & $10^{-3}$ & 94.8 & BDL & 0.02 & 0.39 & 16.5 \\
\hline 17 & 2.7 & 2.7 & 0.3 & 0.9 & BDL & 8.1 & 1.56 & $10^{-3}$ & 88.5 & BDL & 0.03 & 0.50 & 20.7 \\
\hline 18 & 3.0 & 3.3 & 0.0 & 2.4 & BDL & 7.5 & 4.95 & $10^{-3}$ & 79.5 & BDL & 0.02 & 0.57 & 22.2 \\
\hline 19 & 3.0 & 3.6 & 0.3 & 2.1 & BDL & 6.9 & 3.15 & $10^{-3}$ & 72.9 & BDL & 0.02 & 0.68 & 26.1 \\
\hline 20 & 1.5 & 1.2 & 0.0 & 0.6 & 0.0 & 6.3 & $1.8>$ & $10^{-3}$ & 109.5 & BDL & 0.02 & 0.24 & 16.2 \\
\hline 21 & 2.4 & 1.8 & 0.3 & 1.5 & BDL & 6.3 & 3.48 & $10^{-3}$ & 70.2 & BDL & 0.03 & 0.53 & 19.8 \\
\hline 22 & 9.3 & 9.9 & 3.9 & 4.6 & 2.7 & 13.5 & & & 66.3 & BDL & 0.02 & 0.61 & 41.4 \\
\hline 23 & 5.1 & 5.7 & 1.8 & 3.9 & 0.6 & 10.5 & & & 67.8 & BDL & 0.02 & 0.73 & 37.2 \\
\hline 24 & 5.7 & 9.3 & 0.9 & 6.0 & BDL & 9.9 & & & 53.7 & BDL & 0.02 & 1.17 & 44.7 \\
\hline 25 & 8.1 & 9.6 & 0.6 & 5.4 & BDL & 12.9 & & & 42.3 & BDL & 0.02 & 1.62 & 88.5 \\
\hline 26 & 5.4 & 8.1 & 0.3 & 4.5 & 0.3 & 15.6 & & & 69.9 & BDL & 0.04 & 0.71 & 103.8 \\
\hline
\end{tabular}


Table A1. Cont.

\begin{tabular}{|c|c|c|c|c|c|c|c|c|c|c|c|c|}
\hline \multirow{2}{*}{ Sample ID } & \multicolumn{12}{|c|}{ Fraction \#4 (F4: Oxidizable) } \\
\hline & $\mathrm{Cr}$ & Co & $\mathrm{Cu}$ & $\mathbf{N i}$ & $\mathrm{Cd}$ & $\mathrm{Pb}$ & $\mathbf{K}^{*}$ & Se & As & $\mathrm{Al}$ * & $\mathrm{Fe}^{*}$ & Zn \\
\hline 1 & 0.90 & 0.00 & 0.36 & 0.12 & 0.03 & 0.81 & $0.03 \%$ & 0.19 & BDL & $3.84 \times 10^{-3}$ & 0.01 & 0.00 \\
\hline 2 & 0.60 & 0.03 & 0.57 & 0.18 & 0.03 & 0.63 & $0.04 \%$ & 5.64 & BDL & 0.01 & 0.01 & 3.00 \\
\hline 3 & 1.80 & 0.66 & 3.18 & 0.87 & BDL & 0.75 & $0.08 \%$ & BDL & BDL & 0.02 & 0.16 & 0.18 \\
\hline 4 & 1.44 & 1.47 & 1.86 & 1.32 & BDL & 0.90 & $0.12 \%$ & BDL & BDL & 0.04 & 0.11 & 3.12 \\
\hline 5 & 3.30 & 1.53 & 3.96 & 1.38 & BDL & 0.03 & $0.04 \%$ & BDL & $\mathrm{BDL}$ & 0.08 & 0.39 & 12.63 \\
\hline 6 & 2.58 & 1.38 & 8.97 & 1.86 & BDL & 0.12 & $0.02 \%$ & BDL & BDL & 0.06 & 0.37 & 14.04 \\
\hline 7 & 0.48 & 1.50 & 5.94 & 1.05 & BDL & 0.15 & $0.08 \%$ & BDL & BDL & 0.08 & 0.39 & 12.03 \\
\hline 8 & 0.51 & 0.66 & 0.33 & 0.30 & 0.00 & 0.57 & $0.04 \%$ & 2.46 & BDL & 0.02 & 0.01 & 1.89 \\
\hline 9 & 0.75 & 0.78 & 0.39 & 0.36 & 0.00 & 0.72 & $0.05 \%$ & 2.13 & BDL & 0.02 & 0.01 & 2.28 \\
\hline 10 & 2.91 & 4.38 & 129.51 & 3.06 & BDL & BDL & $0.19 \%$ & BDL & BDL & 0.14 & 0.54 & 137.31 \\
\hline 11 & 3.18 & 4.02 & 5.64 & 2.97 & BDL & BDL & $0.10 \%$ & BDL & BDL & 0.19 & 0.65 & 17.70 \\
\hline 12 & 0.54 & 0.18 & 0.18 & 0.18 & 0.00 & 0.54 & $0.03 \%$ & 2.52 & BDL & 0.01 & 0.01 & 0.60 \\
\hline 13 & 0.72 & 0.27 & 0.30 & 0.21 & 0.00 & 0.78 & $0.06 \%$ & 2.49 & BDL & 0.01 & 0.01 & 1.08 \\
\hline 14 & 1.98 & 0.21 & 2.04 & 0.51 & BDL & 0.75 & $0.08 \%$ & BDL & BDL & 0.03 & 0.10 & 0.72 \\
\hline 15 & 1.38 & 0.27 & 1.23 & 0.39 & BDL & 0.69 & $0.07 \%$ & 0.06 & BDL & 0.02 & 0.05 & 0.75 \\
\hline 16 & 2.34 & 0.57 & 2.46 & 0.66 & BDL & 0.63 & $0.11 \%$ & BDL & BDL & 0.04 & 0.13 & 1.14 \\
\hline 17 & 1.05 & 0.45 & 0.84 & 0.30 & BDL & 0.81 & $0.07 \%$ & 0.60 & BDL & 0.02 & 0.04 & 1.23 \\
\hline 18 & 1.80 & 1.89 & 3.45 & 1.74 & BDL & 0.93 & $0.18 \%$ & BDL & BDL & 0.07 & 0.20 & 5.19 \\
\hline 19 & 1.23 & 0.87 & 1.86 & 0.78 & BDL & 0.96 & $0.10 \%$ & BDL & BDL & 0.04 & 0.10 & 2.79 \\
\hline 20 & 1.23 & 0.30 & 1.59 & 0.33 & BDL & 0.75 & $0.06 \%$ & BDL & BDL & 0.02 & 0.08 & 0.96 \\
\hline 21 & 1.26 & 0.51 & 2.10 & 0.72 & BDL & 0.60 & $0.10 \%$ & BDL & BDL & 0.04 & 0.15 & 1.71 \\
\hline 22 & 4.05 & 1.77 & 5.58 & 1.38 & BDL & 0.69 & $0.21 \%$ & BDL & BDL & 0.10 & 0.45 & 6.51 \\
\hline 23 & 4.29 & 4.05 & 9.30 & 3.36 & BDL & 0.03 & $0.05 \%$ & BDL & BDL & 0.19 & 0.73 & 17.94 \\
\hline 24 & 4.23 & 1.35 & 6.33 & 1.92 & BDL & 0.06 & $0.23 \%$ & BDL & BDL & 0.12 & 0.50 & 8.64 \\
\hline 25 & 2.85 & 3.45 & 6.33 & 2.58 & BDL & BDL & $0.19 \%$ & BDL & BDL & 0.16 & 0.57 & 24.66 \\
\hline 26 & 7.23 & 3.15 & 13.95 & 2.40 & BDL & BDL & $0.25 \%$ & BDL & BDL & 0.28 & ND & 23.85 \\
\hline
\end{tabular}

\section{Appendix B}

Spatial heat maps for the bioavailable PTEs. Spatial distribution maps of the bioavailable PTEs.

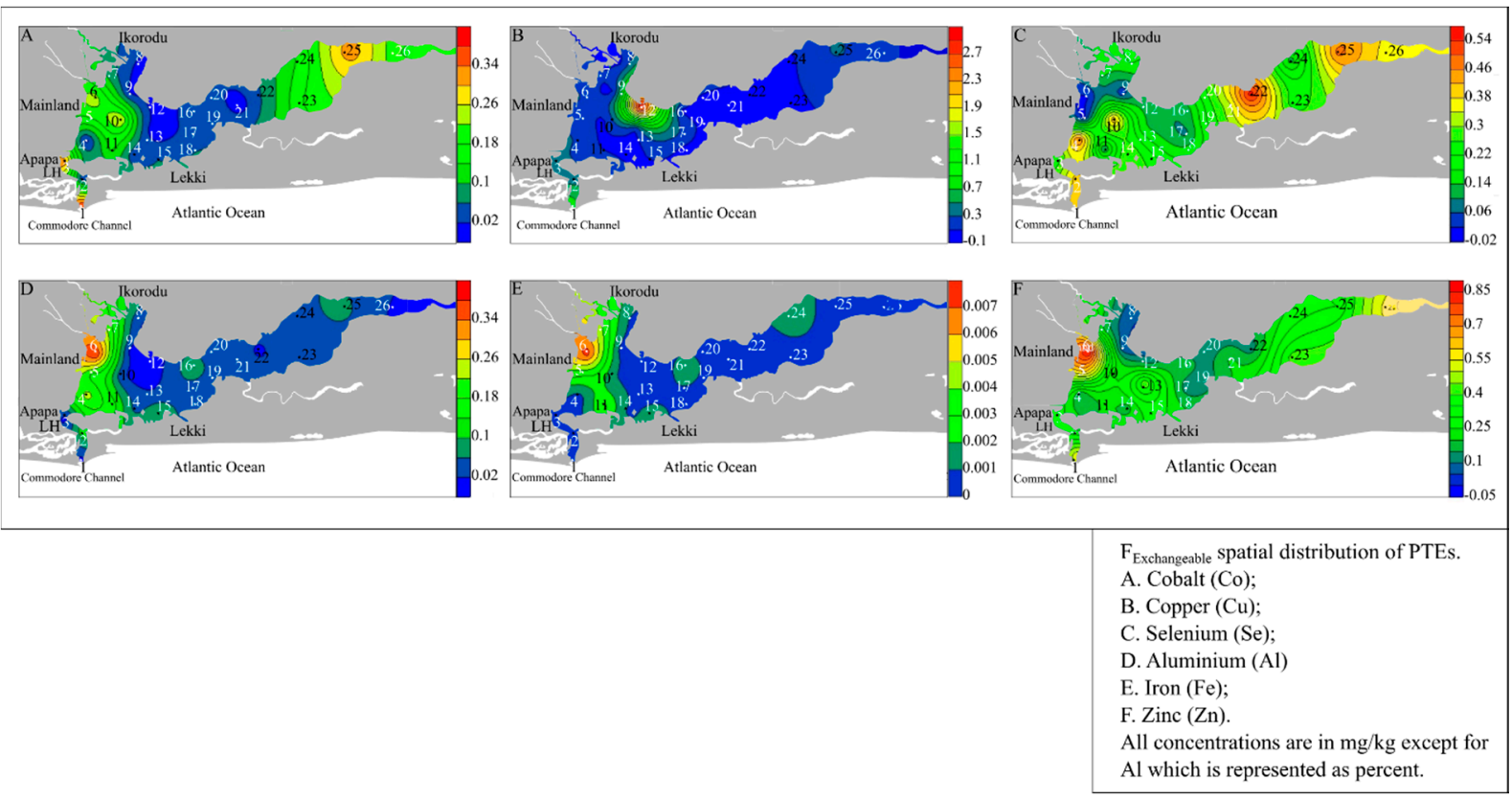

Figure A1. Exchangeable fractions heat maps. 


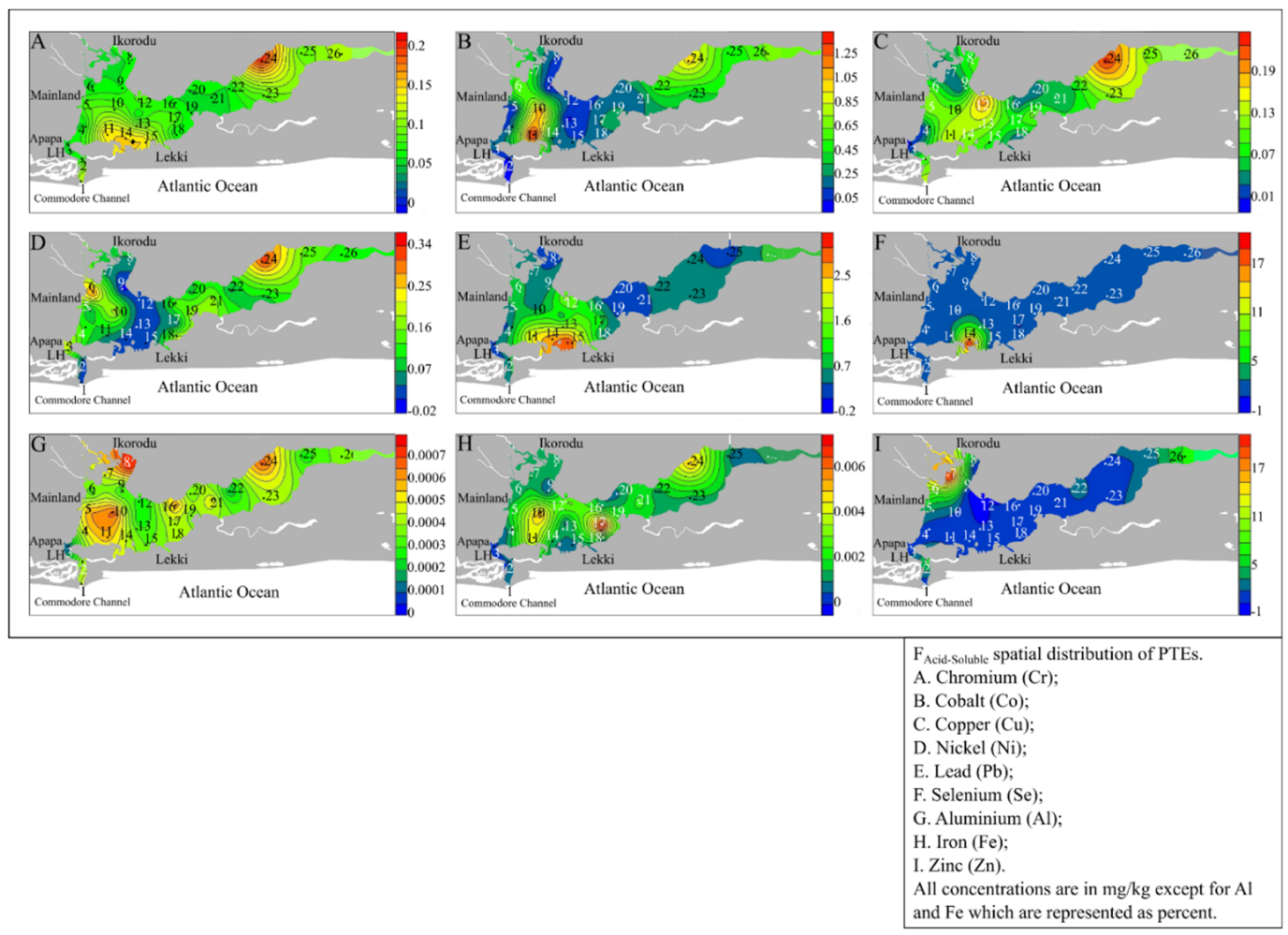

Figure A2. Acid-soluble fractions heat maps.
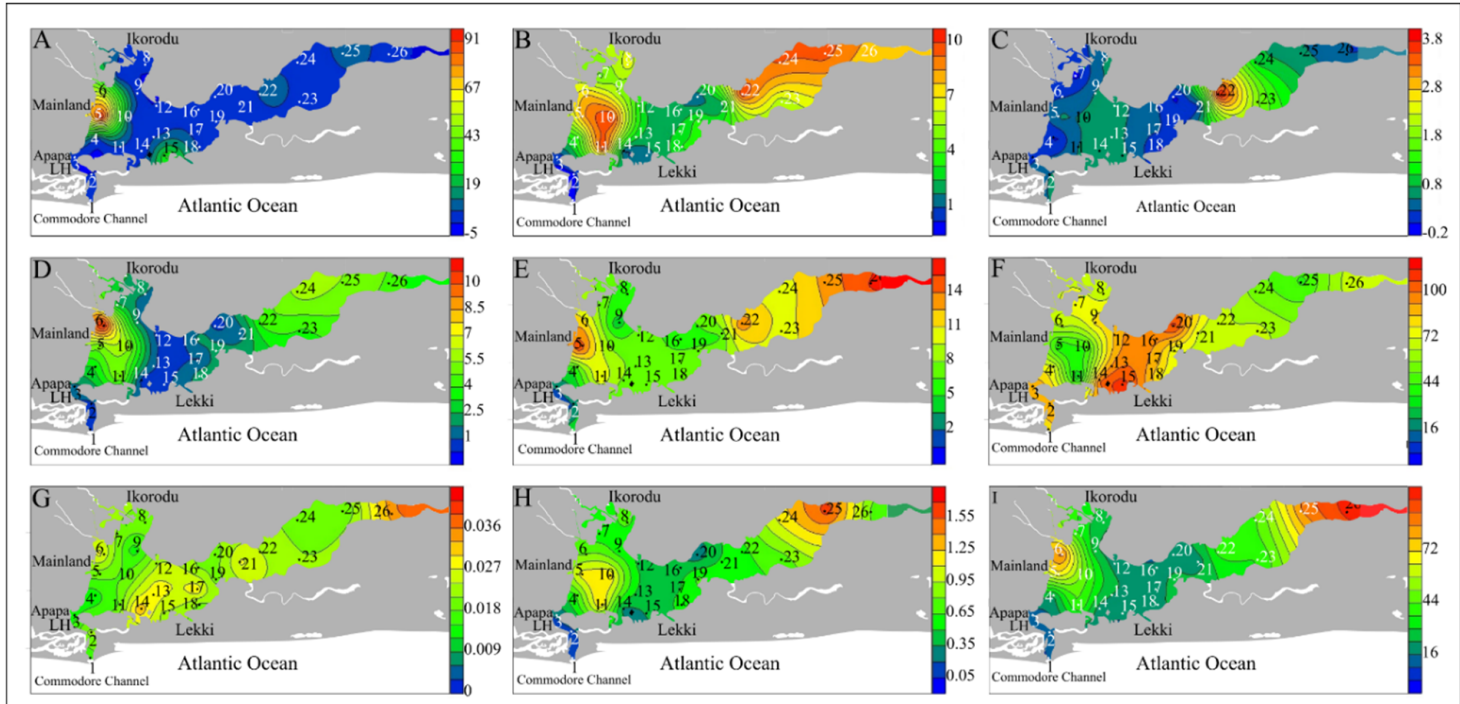

$\mathrm{F}_{\text {Reducible }}$ spatial distribution of PTEs.

A. Chromium $(\mathrm{Cr})$

B. Cobalt (Co);

C. Copper $(\mathrm{Cu})$;

D. Nickel (Ni);

E. Lead $(\mathrm{Pb})$;

F. Selenium (Se);

G. Aluminium (Al);

H. Iron (Fe);

I. Zinc $(\mathrm{Zn})$

All concentrations are in $\mathrm{mg} / \mathrm{kg}$ except for $\mathrm{Al}$

and $\mathrm{Fe}$ which are represented as percent.

Figure A3. Reducible fractions heat maps. 

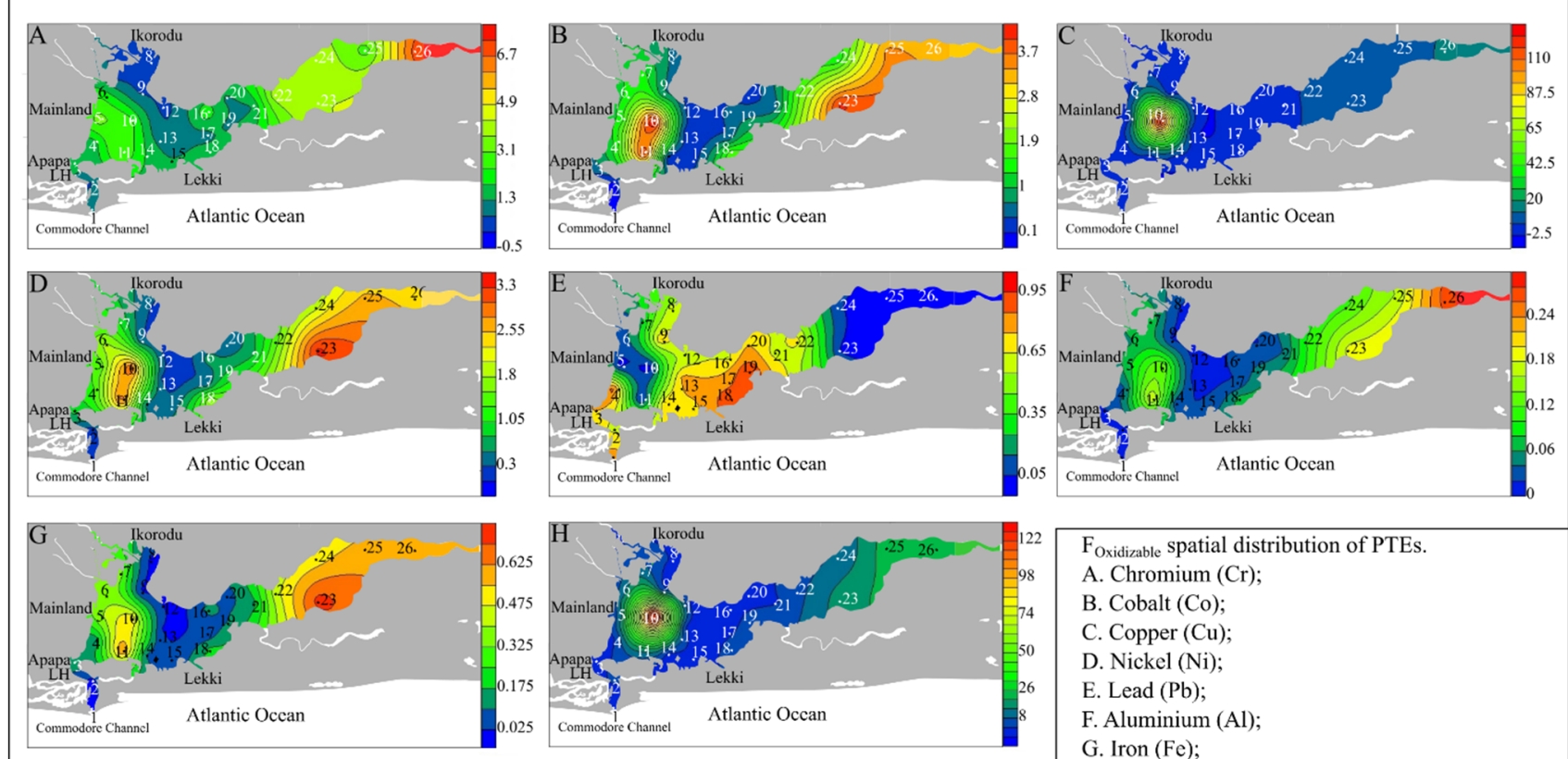
F Oxidizable spatial distribution of PTEs.
A. Chromium (Cr);
B. Cobalt (Co);
C. Copper $(\mathrm{Cu})$
D. Nickel (Ni);
E. Lead $(\mathrm{Pb})$;
F. Aluminium (Al);
G. Iron (Fe);
H. Zinc $(\mathrm{Zn})$.
All concentrations are in $\mathrm{mg} / \mathrm{kg}$ except for $\mathrm{Al}$
and $\mathrm{Fe}$ which are represented as percent.

Figure A4. Oxidizable fractions heat maps.

\section{References}

1. Martínez-Colón, M.; Hallock, P.; Green-Ruíz, C.; Smoak, J.M. Benthic foraminifera as bioindicators of potentially toxic element (PTE) pollution: Torrecillas Lagoon (San Juan Bay Estuary), Puerto Rico. Ecol. Indic. 2018, 89, 516-527. [CrossRef]

2. Li, T.; Li, X.; Zhong, H.; Yang, C.; Sun, G.; Luo, W. Distribution of trace metals and the benthic foraminiferal assemblage as a characterization of the environment in the north Minjiang River Estuary (Fujian, China). Mar. Pollut. Bull. 2015, 90, $227-241$. [CrossRef] [PubMed]

3. Debenay, J.-P.; Pages, J.; Diouf, P.S. Ecological zonation of the hyperhaline estuary of the Casamance River (Senegal): Foraminifera, zooplankton and abiotic variables. Hydrobiologia 1989, 174, 161-176. [CrossRef]

4. Ekett, S.I.; Fred-Ahmadu, O.H.; Adedapo, A.E.; Benson, N.U. Trace and major elements distribution in coastal sediment cores from Lagos Lagoon, Nigeria. Data Brief 2018, 16, 93-100. [CrossRef]

5. Sogbanmu, T.O.; Nagy, E.; Phillips, D.H.; Arlt, V.M.; Otitoloju, A.A.; Bury, N.R. Lagos Lagoon sediment organic extracts and polycyclic aromatic hydrocarbons induce embryotoxic, tetratogenic and genotoxic effects in Danio rerio (zebrafish) embryos. Environ. Sci. Pollut. Res. 2016, 23, 14489-14501. [CrossRef]

6. Ajao, E.A. Review of the state of pollution of the Lagos Lagoon. NIOMR Tech. Pap. 1996, 106, 19.

7. Ajao, E.A.; Fagade, S.O. A study of the sediments and communities in Lagos Lagoon, Nigeria. Oil Chem. Pollut. 1990, 7, 85-117. [CrossRef]

8. Obi, C.C.; Adebusoye, S.A.; Ugoji, E.O.; Ilori, M.O.; Amund, O.O.; Hickey, W.J. Microbial Communities in sediments of Lagos Lagoon, Nigeria: Elucidation of Community Structure and potential Impacts of contamination by municipal and industrial wastes. Front. Microbiol. 2016, 7, 1213. [CrossRef]

9. Ellison, R.L.; Broome, R.; Oglivie, R. Foraminiferal response to trace metal contamination in the Patapsco River and Baltimore harbour, Maryland. Mar. Pollut. Bull. 1986, 17, 419-423. [CrossRef]

10. Frontalini, F.; Coccioni, R.; Bucci, C. Benthic foraminiferal assemblages and trace element contents from the lagoons of Orbetello and Lesina. Environ. Monit. Assess. 2010, 170, 245-260. [CrossRef] [PubMed]

11. Martins, M.V.A.; Helali, M.A.; Zaaboub, N.; Boukef-BenOmrane, I.; Frontalini, F.; Reis, D.; Portela, H.; Clemente, I.M.M.M.; Nogueira, L.; Pereira, E.; et al. Organic matter quantity and quality, metals availability and foraminiferal assemblages as environmental proxy applied to the Bizerte Lagoon (Tunisia). Mar. Pollut. Bull. 2016, 105, 161-179. [CrossRef]

12. Suokhrie, T.; Saraswat, R.; Nigam, R. Foraminifera as Bio-Indicators of Pollution: A Review of Research over the Last Decade. Micropaleontology and its Applications; Pradeep, K.K., Rajiv, N., Abu, T., Eds.; Sci. Publ.: Delhi, India, 2017; pp. $265-284$.

13. Fajemila, O.T.; Sariaslan, N.; Langer, M.R. Spatial Distribution of Benthic Foraminifera in the Lagos Lagoon (Nigeria): Tracing the Impact of Environmental Perturbations. PLOS ONE 2020, 15, e243481. [CrossRef]

14. Hill, M.B.; Webb, J.E. The ecology of Lagos Lagoon-Part II. The topography and physical features of Lagos Harbour and Lagos Lagoon. Philos. Trans. R. Soc. 1957, 241, 319-333. 
15. Emmanuel, B.E.; Chukwu, L.O. Spatial distribution of saline water and possible sources of intrusion into a tropical freshwater lagoon and the transitional effects on the lacustrine ichthyofaunal diversity. Afr. J. Eniron. Sci. Technol. 2010, 4, 480-491.

16. Nkwoji, J.A.; Ugbana, S.I.; Ina-Salwany, M.Y. Impacts of land-based pollutants on water chemistry and benthic macroinvertebrates community in a coastal lagoon, Lagos, Nigeria. Sci. Afr. 2020, 7, e00220. [CrossRef]

17. Nkwoji, J.A.; Awodeyi, S.I. Impacts of sediment mining on the hydrochemistry and macrozoobenthos community in a coastal lagoon, Lagos, Nigeria. Arch. Agric. Environ. Sci. 2018, 3, 209-215. [CrossRef]

18. Lawson, E.O. Physico-chemical parameters and heavy metal contents of water from the mangrove swamps of the Lagos Lagoon, Nigeria. Adv. Biol. Res. 2011, 5, 8-21.

19. Okoye, B.C.O.; Afolabi, O.A.; Ajao, E.O. Heavy metals in the Lagos Lagoon sediments. Int. J. Environ. Stud. 1991, 37, 35-41. [CrossRef]

20. Heiri, O.; Lotter, A.F.; Lemcke, G. Loss on ignition as a method for estimating organic and carbonate content in sediments: Reproducibility and comparability of results. J. Paleolimnol. 2001, 25, 101-110. [CrossRef]

21. Jacq, K.; Perrette, Y.; Fenger, B.; Sabatier, P.; Coquin, D.; Martinez-Lamas, R.; Debret, M.; Arnaud, F. High-resolution prediction of organic matter concentration with hyperspectral imaging on a sediment core. Sci. Total Environ. 2019, 663, 236-244. [CrossRef]

22. Tessier, A.; Campbell, P.G.C.; Bisson, M. Sequential Extraction Procedure for the Speciation of Particulate Trace Metals. Anal. Chem. 1979, 51, 844-851. [CrossRef]

23. Parker, W.C.; Arnold, A.J. Quantitative methods of data analysis in foraminiferal ecology. In Modern Foraminifera; Sen, G.B.K., Ed.; Kluwer: Dordrecht, The Netherlands, 1999; pp. 71-89.

24. Turekian, K.K.; Wedepohl, K.H. Distribution of elements in some major units of the earth's crust. Geol. Soc. Am. Bull. 1961, 72, 175-192. [CrossRef]

25. Liaghati, T.; Preda, M.; Cox, M. Heavy metal distribution and controlling factors within coastal plain sediments, bells creek catchments, Southeast Queensland, Australia. Environ. Int. 2003, 29, 935-948. [CrossRef]

26. Abdel Ghani, S.A. Trace metals in seawater, sediments and some fish species from Marsa Matrouh Beaches in north-western Mediterranean coast, Egypt. Egypt. J. Aquat. Res. 2015, 41, 145-154. [CrossRef]

27. Hakanson, L. An ecological risk index for aquatic pollution control. A sedimentological approach. Water Res. 1980, 14, 975-1001. [CrossRef]

28. Hammer, Ø.; Harper, D.A.T.; Ryan, P.D. PAST: Paleontological statistics software package for education and data analysis Palaeontol. Electron. 2001, 4, 1-9.

29. Dehghan-Madiseh, S.; Savari, A.; Parham, H.; Marmmazy, J.; Papahn, F.; Sabzalizadeh, S. Heavy metals contaminant evaluation of Khour-e-Musa creeks., northwest of Persian Gulf. Iran. J. Fish. Sci. 2008, 7, 137-156.

30. Sulaiman, M.B.; Salawu, K.; Barambu, A.U. Assessment of Concentrations and Ecological Risk of Heavy Metals at Resident and Remediated Soils of Uncontrolled Mining Site at Dareta Village, Zamfara, Nigeria. J. Appl. Sci. Environ. Manag. 2019, 23, 187-193. [CrossRef]

31. Van Bentum, K.M. Lagos Coast: Investigation of the Long-Term Morphological Impact of the Eko Atlantic City Project. Master's Thesis, Delft University of Technology, Delft, The Netherlands, 2012; 223p.

32. Onyena, A.P.; Okoro, C.A. Spatio-temporal variations in water and sediment parameters of Abule Agege, Abule Eledu, Ogbe, creeks adjoining Lagos Lagoon, Nigeria. J. Ecol. Nat. Environ. 2019, 11, 46-54. [CrossRef]

33. Brady, J.P.; Ayoko, G.A.; Martens, W.N.; Goonetilleke, A. Development of a hybrid pollution index for heavy metals in marine and estuarine sediments. Environ. Monit. Assess. 2015, 187, 306. [CrossRef]

34. Mennilo, E.; Adeogun, A.; Arukwe, A. Quality screening of the Lagos lagoon sediment by assessing the cytotoxicity and toxicological responses of rat hepatoma H4IIE and fish PLHC-1 cell-lines using different extraction approaches. Environ. Res. 2020, 182, 108986. [CrossRef]

35. Don-Pedro, K.N.; Oyewo, E.O.; Otitoloju, A.A. Trend of heavy metal concentrations in Lagos Lagoon ecosystem, Nigeria. West Afr. J. Appl. Ecol. 2004, 5, 103-114. [CrossRef]

36. Bawa-Allah, K.A.; Saliu, J.K.; Otitoloju, A.A. Heavy Metal Pollution Monitoring in Vulnerable Ecosystems: A Case Study of the Lagos Lagoon, Nigeria. Bull. Environ. Contam. Toxicol. 2018, 100, 609-613. [CrossRef]

37. Martínez-Colón, M.; Hallock, P.; Green-Ruíz, C. Strategies for using shallow-water benthic foraminifers as bioindicators of potentially toxic elements: A review. J. Foraminifer. Res. 2009, 39, 278-299. [CrossRef]

38. Martins, M.V.A.; Hohenegger, J.; Martínez-Colón, M.; Frontalini, F.; Bergamashi, S.; Laut, L.; Belart, P.; Mahiques, M.; Pereira, E.; Rodrigues, R.; et al. Ecological quality status of the NE sector of the Guanabara Bay (Brazil): A case of living benthic foraminiferal resilience. Mar. Pollut. Bull. 2020, 158, 111449. [CrossRef]

39. Hassani, S.; Karbassi, A.R.; Ardestani, M. Role of estuarine natural flocculation process in removal of $\mathrm{Cu}, \mathrm{Mn}, \mathrm{Ni}, \mathrm{Pb}$ and $\mathrm{Zn}$. Glob. J. Environ. Sci. Manag. 2017, 3, 187-196.

40. Frontalini, F.; Buosi, C.; Da Pelo, S.; Coccioni, R.; Cherchi, A.; Bucci, C. Benthic foraminifera as bio-indicators of trace element pollution in the heavily contaminated Santa Gilla lagoon (Cagliari, Italy). Mar. Pollut. Bull. 2009, 58, 858-877. [CrossRef]

41. Shaheen, S.M.; Abdelrazek, M.A.S.; Elthoth, M.; Moghanm, F.S.; Mohamed, R.; Hamza, A.; El-Habashi, N.; Wang, J.; Rinklebe, J. Potentially toxic elements in saltmarsh sediments and common reed (Phragmites australis) of Burullus coastal lagoon at North Nile Delta, Egypt: A survey and risk assessment. Sci. Total Environ. 2019, 649, 1237-1249. [CrossRef] 
42. Peters, G.M.; Maher, W.A.; Barford, J.P.; Gomes, V.G. Selenium associations in estuarine sediments: Redox effects. Water Air Soil Pollut. 1997, 99, 275-282. [CrossRef]

43. Owoade, O.K.; Olise, F.S.; Obioh, I.B.; Olaniyi, H.B.; Ferrero, L.; Bolzacchini, E. EDXRF elemental assay of airborne particulates: A case study of an iron and steel smelting industry, Lagos, Nigeria. Sci. Res. Essay 2009, 4, 1342-1347.

44. Olatunji, A.S.; Kolawole, T.O.; Oloruntola, M.; Günter, G. Evaluation of pollution of soils and particulate matter around metal recycling factories in southwestern Nigeria. J. Health Pollut. 2018, 8, 20-30. [CrossRef]

45. Anderson, C.S. Mineral Yearbook. Selenium and Tellurium. Advanced Release; 2016; pp. 1-9. Available online: https: //www.usgs.gov/centers/national-minerals-information-center/selenium-and-tellurium-statistics-and-information (accessed on 23 November 2021).

46. May, T.W.; Fairchild, J.F.; Petty, J.D.; Walther, M.J.; Lucero, J.; Delvaux, M.; Manring, J.; Armbruster, M. An evaluation of selenium concentrations in water, sediment, invertebrates, and fish from the Solomon River Basin. Environ. Monit. Assess. 2008, 137, 213-232. [CrossRef]

47. Lemly, A.D. Interpreting selenium concentrations. In Selenium Assessment in Aquatic Ecosystems: A Guide for Hazard Evaluation and Water Quality Criteria; Alexander, D.E., Ed.; Springer: Berlin/Heidelberg, Germany, 2002; pp. 18-38.

48. Lemly, A.D. Toxicology of selenium in a freshwater reservoir: Implications for environmental hazard evaluation and safety. Ecotoxicol. Environ. Saf. 1985, 10, 314-338. [CrossRef]

49. Overah, C.L.; Iwegbue, C.M.A.; Ossai, E.K.; Nwajei, G.E. Trace elements in sediments of selected gutters and Bar-Beach, Lagos, Nigeria. J. Appl. Sci. Environ. Manag. 2012, 16, 253-255.

50. El Baz, S.M.; Khalil, M.M. Benthic foraminifera and trace metal distribution: A case study from the Burullus Lagoon, Egypt. Rev. Micropaléontol. 2018, 61, 97-109. [CrossRef]

51. Elshanawany, R.; Ibrahim, M.I.; Milker, Y.; Schmiedl, G.; Badr, N.; Kholeif, S.E.A.; Zonneveld, K.A.F. Anthropogenic impact on benthic foraminifera, Abu-Qir Bay, Alexandria, Egypt. J. Foraminifer. Res. 2011, 41, 326-348. [CrossRef]

52. Ferraro, L.; Sprovieri, M.; Alberico, I.; Lirer, F.; Prevedello, L.; Marsella, E. Benthic foraminifera and heavy metals distribution: A case study from the Naples Harbour (Tyrrhenian Sea, Southern Italy). Environ. Pollut. 2006, 142, 274-287. [CrossRef]

53. Martínez-Colón, M.; Hallock, P.; Green-Ruíz, C.; Smoak, J.M. Temporal variability in potentially toxic elements (PTE's) and benthic Foraminifera in an estuarine environment in Puerto Rico. Micropaleontology 2017, 63, 357-381.

54. Murray, J.W. Ecology and Applications of Benthic Foraminifera; Cambridge University Press: Cambridge, UK; New York, NY, USA; Melbourne, Australia, 2006.

55. Langer, M.R.; Lipps, J.H. Foraminiferal distribution and diversity, Madang reef and lagoon, Papua New Guinea. Coral Reefs 2003, 22, 143-154. [CrossRef]

56. Sariaslan, N.; Langer, M.R. Atypical, high-diversity assemblages of foraminifera in a mangrove estuary in northern Brazil. Biogeosciences 2021, 18, 4073-4090. [CrossRef]

57. Fajemila, O.T.; Langer, M.R.; Lipps, J.H. Atlas of Shallow-Water Tropical Benthic Foraminifera from Moorea (Society Islands, French Polynesia). Cushman Found. Spec. Publ. 2020, 48, 107.

58. Fajemila, O.T.; Langer, M.R. Ecosystem indicators: Foraminifera, Thecamoebians and Diatoms from the Ologe Lagoon, Nigeria. Rev. Micropaléontol. 2016, 59, 397-407. [CrossRef]

59. Langer, M.R.; Mouanga, G.H.; Fajemila, O.T. Shallow-water nearshore benthic foraminifera assemblages from Gabon. Micropaleontology 2016, 62, 69-80.

60. Langer, M.R.; Fajemila, O.T.; Mannl, S. Assemblages of recent intertidal mangrove foraminifera from the Akanda National Park, Gabon: Sea level proxies preserved in faunal assemblages. Neues Jahrb. Geol. Paläontol. Abh. 2016, 281, 327-338. [CrossRef]

61. Debenay, J.P. Recent foraminiferal assemblages and their distribution relative to environmental stress in the paralic environments of west African (Cape Timiris to Ebrie Lagoon). J. Foraminifer. Res. 1990, 20, 267-282. [CrossRef]

62. Hayward, B.W.; Holzmann, M.; Pawlowski, J.; Parker, J.H.; Kaushik, T.; Toyofuku, M.S.; Tsuchiya, M. Molecular and morphological taxonomy of living Ammonia and related taxa (Foraminifera) and their biogeography. Micropaleontology 2021, 67, 109-313.

63. Langer, M.R.; Lipps, J.H. Assembly and persistence of foraminifera in introduced Mangroves on Moorea, French Polynesia. Micropaleontology 2006, 52, 343-355. [CrossRef]

64. Lipps, J.H.; Langer, M.R. Benthic foraminifera from the meromictic Mecherchar Jellyfish Lake, Palau (western Pacific). Micropaleontology 1999, 45, 278-284. [CrossRef]

65. Le Cadre, V.; Debenay, J.-P.; Lesourd, M. Low pH effects on Ammonia beccarii test deformation: Implications for using test deformation as a pollution indicator. J. Foraminifer. Res. 2003, 33, 1-9. [CrossRef]

66. Pettit, L.R.; Hart, M.B.; Medina-Sánchez, A.N.; Smart, C.W.; Rodolfo-Metalpa, R.; Hall-Spencer, J.M.; Prol-Ledesma, R.M. Benthic foraminifera show some resilience to ocean acidification in the northern Gulf of California, Mexico. Mar. Pollut. Bull. 2013, 73, 452-462. [CrossRef]

67. Dias, B.; Hart, M.; Smart, C.; Hall-Spencer, J. Modern seawater acidification: The response of foraminifera to high-CO ${ }_{2}$ conditions in the Mediterranean Sea. J. Geol. Soc. 2010, 167, 843-846. [CrossRef]

68. Bergin, F.; Kucuksezgin, F.; Uluturhan, E.; Barut, I.F.; Meric, E.; Avsar, N.; Nazik, A. The response of benthic foraminifera and ostracoda to heavy metal pollution in Gulf of Izmir (Eastern Aegean Sea). Estuar. Coast. Shelf Sci. 2006, 66, 368-386. [CrossRef] 
69. Schintu, M.; Marrucci, A.; Marras, B.; Galgani, F.; Buosi, C.; Ibba, A.; Cherchi, A. Heavy metal accumulation in surface sediments at the port of Cagliari (Sardinia, western Mediterranean): Environmental assessment using sequential extraction and benthic foraminifera. Mar. Pollut. Bull. 2016, 111, 45-56. [CrossRef]

70. Alve, E. Benthic foraminifera response to estuarine pollution: A review. J. Foraminifer. Res. 1995, 25, 190-203. [CrossRef]

71. Yanko, V.; Ahmad, A.; Bresler, V. Morphological deformities of benthic foraminiferal tests in response to pollution by heavy metals: Implications for pollution monitoring. J. Foraminifer. Res. 1998, 28, 177-200.

72. Brouillette Price, E.; Kabengi, N.; Goldstein, S.T. Effects of heavy-metal contaminants (Cd, Pb, Zn) on benthic foraminiferal assemblages grown from propagules, Sapelo Island, Georgia (USA). Mar. Micropaleontol. 2019, 147, 1-11. [CrossRef]

73. Smith, C.W.; Goldstein, S.T. The Effects of Selected Heavy Metal Elements (Arsenic, Cadmium, Nickel, Zinc) On Experimentally Grown Foraminiferal Assemblages from Sapelo Island, Georgia and Little Duck Key, Florida, U.S.A. J. Foraminifer. Res. 2019, 49, 303-317. [CrossRef]

74. Smith, C.W.; Goldstein, S.T. Effects of Varied Temperature and Salinity on Assemblages of Foraminifera Grown with Exposure to Heavy-Metal Pollutants (Nickel and Zinc). J. Foraminifer. Res. 2021, 51, 99-114.

75. Armynot du Chatelet, E.; Gebhardt, K.; Langer, M.R. Coastal pollution monitoring: Foraminifera as tracers of environmental perturbation in the port of Boulogne-sur-Mer (Northern France). Neues Jahrb. Geol. Paläontol. Abh. 2011, 262, 91-116. [CrossRef]

76. Alani, R.; Drouillard, K.; Olayinka, K.; Alo, B. Bioaccumulation of organochlorine pesticide residues in fish and invertebrates of Lagos Lagoon, Nigeria. Am. J. Sci. Ind. Res. 2013, 4, 22-30. [CrossRef]

77. Benson, N.U.; Fred-Ahmadu, O.H.; Ekett, S.I.; Basil, M.O.; Adebowale, A.D.; Adewale, A.G.; Ayejuyo, O.O. Occurrence, depth distribution and risk assessment of PAHs and PCBs in sediment cores of Lagos lagoon, Nigeria. Reg. Stud. Mar. Sci. 2020, 37, 101335. [CrossRef] 